\title{
Implementing Partial Tax Harmonization in an Asymmetric Tax Competition Game with Repeated Interaction
}

\author{
Jun-ichi Itaya \\ Makoto Okamura \\ Chikara Yamaguchi
}

CESIFO WORKING PAPER NO. 5312

CATEGORY 1: PUBLIC FINANCE

APRIL 2015

An electronic version of the paper may be downloaded

- from the SSRN website:

- from the RePEc website:

- from the CESifo website:

wWw.SSRN.com

Www.RePEc.org

www.CESifo-group.org/wp 


\title{
Implementing Partial Tax Harmonization in an Asymmetric Tax Competition Game with Repeated Interaction
}

\begin{abstract}
This paper investigates the conditions under which partial harmonization for capital taxation is sustained in a repeated interactions model of tax competition when there are three countries with heterogenous capital endowments. We show that regardless of the structure of the coalition (i.e. full or partial tax coordination), whether partial tax harmonization is sustainable or not crucially depends on the extent to which the capital endowment of the medium-sized country is similar to that of the large or small country. The most noteworthy finding is that the closer the capital endowment of the median country is to the average one, the less likely the tax harmonization including the median country is to prevail and the more likely the partial tax harmonization excluding the median country is to prevail. We also show that partial tax harmonization makes the member countries of the tax union better off and non-member countries worse off, which stands in shape contrast with previous studies such as Konrad and Schjelderup (1999) and Bucovetsky (2009).
\end{abstract}

JEL-Code: H730, F590, F210.

Keywords: tax coordination, asymmetric countries, repeated game, tax competition.

Jun-ichi Itaya
Graduate School of Economics and
Business Administration
Hokkaido University
Japan - Sapporo 060-0809
itaya@econ.hokudai.ac.jp

Jun-ichi Itaya

Chikara Yamaguchi*

Faculty of Economic Sciences

Hiroshima Shudo University

1-1-1 Ozukahigashi, Asaminamiku

Japan - Hiroshima 731-3195

chikara@shudo-u.ac.jp
Makoto Okamura

Economics Department

Hiroshima University

1-2-1 Kagamiyama, Higashihiroshima

Japan - Hiroshima 739-8526

okamuram@hiroshima-u.ac.jp

\section{*corresponding author}

\section{April 12, 2015}

We are indebted to two anonymous referees and journal co-editor Josh Ederington, whose extremely valuable and constructive comments significantly improved the paper. We also thank Keisuke Kawachi, Mutsumi Matsumoto, and Hikaru Ogawa for their helpful comments on the earlier version of the paper. This work was supported by JSPS KAKENHI Grant Numbers 2153029, 20330052, 20730226, and 24530379. 


\section{Introduction}

In the European Union (EU), the harmonization of corporate taxation has been debated since the European Economic Community was established, although the EU has never been successful in implementing any serious cooperation or harmonization in corporate taxation. This has made partial tax harmonization a more attractive and realistic policy option for politicians and economists in seeking to overcome the inefficiency in world capital allocation resulting from non-harmonized capital taxation based on the source principle. Since only a subset of countries need to agree on the harmonized policy for partial tax harmonization, the political constraints are less stringent. Indeed, subsets of EU members (with a minimum of 8 countries) were institutionalized via "Enhanced Cooperation Agreements" (ECA) through the treaties of Amsterdam (1997) and Nice (2003). An ECA can be activated when the 27 member countries cannot all agree to coordinate their policies on a particular issue such as harmonizing corporate tax policy.

Academic concern has been fueled by increasing public debate on partial harmonization through such channels as ECAs, motivating several theoretical papers on tax coordination. Burbidge et al. (1997) analyze endogenous coalition formation for jurisdictional capital tax policy in a standard model of capital tax competition and demonstrate that the grand coalition among all jurisdictions is realized as a unique equilibrium even in a static setting if the number of jurisdictions is only two, but this is not the case if there exist three or more jurisdictions. Konrad and Schjelderup (1999) demonstrate that in the standard static tax competition framework with identical countries, based on the assumption of strategic complementarity between the tax rates of a partial tax union and outside countries, partial harmonization can improve not only the welfare of the union but also that of the outside countries. Kächelein (2004) considers partial harmonization in a model with a large number of symmetric countries and finds that a welfare loss arises for the partial union that implements tax harmonization when it is small relative to the world capital market, while all countries gain from partial harmonization when the union is very large relative to the capital market. Using a model with an arbitrary number of countries that differ in population, Bucovetsky (2009) shows that any partial tax harmonization not only increases the average payoff of the member jurisdictions in the tax union but also benefits the residents of all jurisdictions not in the tax union as well as the largest jurisdiction in the tax union. Using an asymmetric three-country model whose countries differ in size, Vrijburg (2009) shows that partial harmonization induces inside countries to increase their tax rates but outside countries to either increase or decrease their tax rates, while it unambiguously augments 
the welfare levels of the outside countries.

Although such tax coordination (harmonization) among all jurisdictions would be desirable or Pareto-improving compared to a Nash equilibrium in a one-shot tax competition game, it is generally difficult to realize it as an equilibrium in the one-shot game. This is because the structure of payoffs accrued to countries in static (one-shot) tax competition models typically tend to display characteristics of "Prisoners' dilemma," which is mainly caused by a positive fiscal externality associated with tax policies (see Wildasin (1989)); hence, there is a strong incentive for each tax authority to unilaterally deviate from a Pareto-improving coordinated tax rate in the hope of reaping gains such as increased tax revenues or higher welfare levels. As a result, countries fail to implement implicit collusion or explicit agreements for tax coordination without an explicit contractual arrangement that is assumed to be exogenously enforced if signed or supranational agency that could enforce it. In contrast, using repeated interactions models, Cardarelli et al. (2002), Catenaro and Vidal (2006), and Itaya et al. (2008) show that based on Folk Theorem arguments, full tax harmonization can emerge as an self-enforced equilibrium among decentralized jurisdictions as long as sovereign jurisdictions are sufficiently patient. Their implicit coordination mechanism is that repetition allows punishment to be the strategy taken in the future. However, all of these studies focus on the sustainability of full tax coordination; partial tax harmonization is outside the scope of their analyses. The only exception is Itaya et al. (2014), which extends the framework of Konrad and Schjelderup (1999) to a repeated interactions setting consisting of many identical jurisdictions and shows that partial tax coordination can prevail if each jurisdiction in a coalition group is sufficiently patient. They also demonstrate that partial tax coordination is more likely to be sustained as the number of jurisdictions in the coalition becomes smaller and the number of jurisdictions in the entire economy becomes larger.

The purpose of this paper is to investigate the conditions under which partial capital tax harmonization among heterogenous or asymmetric countries in terms of capital endowments is sustained as an equilibrium outcome in a repeated interactions model of tax competition. To do this, we employ a three-country model that is rich enough to capture some of the central features of tax competition between asymmetric countries but simple enough to yield sharp insights into such central questions as the sustainability of partial tax harmonization supported by a tax union consisting of any subset of three heterogenous countries. Peralta and van Ypersele (2006), Bucovetsky (2009), and Vrijburg (2009) use the conventional static tax competition game in which, when countries are asymmetric, some countries might be worse off from tax harmonization compared to tax competition since a given 
country's characteristics determine whether it will be a loser or a winner from tax harmonization; consequently, such inter-jurisdictional conflict discourages some countries from taking part in full tax harmonization. On the other hand, using a repeated interactions model consisting of two asymmetric countries, Cardarelli et al. (2002) and Catenaro and Vidal (2006) show that if the difference in capital endowments, preferences of inhabitants, or, production technologies is sufficiently large, full tax harmonization between two countries is no longer sustainable.

In contrast, we show that tax harmonization supported either by all heterogenous countries or by any subset of heterogenous countries (i.e., full harmonization and partial harmonization between any two heterogenous countries) can be sustained as a subgame perfect equilibrium of the repeated game if the member countries included in the union are sufficiently patient. The most noteworthy finding is that a medium-sized country in terms of capital endowment always plays a crucial role in the successful implementation of tax harmonization among heterogenous countries. More specifically, the closer the capital endowment of the median country is to the average capital endowment of all countries, the less likely full or any partial tax harmonization that includes the median country is to prevail, while the partial tax harmonization that excludes the median country is more likely to prevail. We also show that in our setting, not only does partial tax harmonization make member countries better off and non-member countries worse off, it also potentially Pareto improving if the tax union consists of countries that differ to a large extent in their capital endowments. These results stand in sharp contrast to those of Konrad and Schjelderup (1999), Kächelein (2004), Bucovetsky (2009), and Vrijburg (2009) that have shown that partial tax harmonization can improve not only the welfare of the union but also that of outside countries. This difference stems from the fact that in their models, partial tax harmonization avoids an inefficiently low tax rate, which leads to the underprovision of public goods for all countries through the fiscal externality (the so-called race-to-the-bottom tax competition), whereas in our model, partial tax harmonization not only eliminates the inefficiency of production within the tax union but also creates a strategic motivation to manipulate the prices of capital in their favor (i.e., the pecuniary externality or terms-of-trade effect; see, e.g., DePater and Myers (1994) and Peralta and van Ypersele (2005)) since the net capital-exporting positions of the tax union and the outside country are opposed to each other. In other words, a partial tax union is induced to deliberately distort the harmonized tax rate, thereby unambiguously making the outside country worse off.

The rest of the paper is organized as follows. Section 2 presents the structure of the one-shot tax competition game and characterizes its fully noncooperative Nash equilibrium. Section 3 con- 
structs a repeated interactions model of full tax harmonization wherein all countries cooperate with regard to their tax policies and investigates the likelihood of coordination. Section 4 investigates the sustainability of partial tax harmonization among a subset of countries. Section 5 compares the welfare levels of member and non-member countries between the tax competition without partial tax harmonization and that with partial tax harmonization comprising any subset of the existing countries. Section 6 briefly discusses two extensions of the basic model. Section 7 concludes the paper with several remarks.

\section{The Model}

Consider an economy composed of three countries that are symmetric except for their heterogenous capital endowments. For analytical convenience, we assume that all countries have equal populations. The per capita capital endowments of the large, medium, and small countries, are respectively, represented as $\bar{k}_{i}, i=L, M, S$, with $\bar{k}_{L} \geq \bar{k}_{M} \geq \bar{k}_{S} \cdot{ }^{1}$ It is convenient to express them as follows: $\bar{k}_{L}=(1+\varepsilon) \bar{k}, \bar{k}_{M}=(1+\varepsilon \theta) \bar{k}$ and $\bar{k}_{S}=[1-\varepsilon(1+\theta)] \bar{k}$, where $\bar{k} \equiv\left(\bar{k}_{L}+\bar{k}_{M}+\bar{k}_{S}\right) / 3$ represents the average capital endowment of all countries, $\varepsilon>0$ indicates the discrepancy between $\bar{k}_{L}$ and $\bar{k}$, and $\theta \in[-1 / 2,1]$ determines the position of the median country relative to $\bar{k}$ without changing the aggregate endowment of capital. When $\theta=1(\theta=-1 / 2)$, the capital endowment of country $M$ coincides with that of country $L$ (country $S$ ), while when $\theta=0$, it is equal to the average one $\bar{k}$. Accordingly, when $\theta>0(\theta<0)$, the capital endowment of country $M$ is relatively close to that of country $L($ country $S)$.

In each country, there exist a representative household and a representative firm; workers are immobile across countries while capital is perfectly mobile. These factors are used in the production of a numéraire good. Following Bucovetsky (1991, 2009), Peralta and van Ypersele (2006), and Itaya et al. (2008), we assume the constant-returns-to-scale production function in an intensive form: $f\left(k_{i}\right) \equiv\left(a-k_{i}\right) k_{i}$, where $a>0$ stands for a technology parameter that is assumed to be identical across all countries and $k_{i}$ is the per capita amount of capital demanded in country $i$. We further assume that $a>2 k_{i}$ to ensure the positive marginal productivity of capital. Public expenditures, $g_{i}$, are entirely financed by a source-based tax on capital $\tau_{i}$, so the budget constraint of the government of

\footnotetext{
${ }^{1}$ Alternatively, Bucovetsky (1991) and Wilson (1991) investigate a model with asymmetric populations; i.e., $N_{i} \bar{k}=$ $\bar{K}_{i}$, in their one-shot static tax competition model, where $N_{i}$ and $\bar{K}_{i}$ represent the number of residents and the capital endowment in jurisdiction $i$, respectively, and $\bar{k}$ is the per-capita capital endowment, which is identical across all jurisdictions. For analytical simplicity, we here treat the model as asymmetric in terms of capital endowments $\bar{k}_{i}$ rather than $N_{i}$.
} 
country $i$ is expressed as $g_{i}=\tau_{i} k_{i}$. Given the market prices and the tax rates, the profit-maximizing input choices are characterized by the following first-order conditions: $r=f^{\prime}\left(k_{i}\right)-\tau_{i}=a-2 k_{i}-\tau_{i}$ and $w_{i}=f\left(k_{i}\right)-k_{i} f^{\prime}\left(k_{i}\right)=k_{i}^{2}$, where $r$ is the net return on capital and $w_{i}$ is the country-specific wage rate. $^{2}$ The perfect international mobility of capital ensures that the net return on capital is equalized across all countries. Hence, the capital market equilibrium is characterized by this arbitrage condition for all $i$ and the capital market clearing condition $\sum k_{i}=\bar{k}_{L}+\bar{k}_{M}+\bar{k}_{S}=3 \bar{k}$, where $k_{i}=\left(a-r-\tau_{i}\right) / 2$, $i=L, M, S$ denotes country $i$ 's capital demand function. In equilibrium, the net return on capital and the amount of capital demanded in country $i$ are given respectively as follows:

$$
\begin{aligned}
& r^{*}=a-2 \bar{k}-\bar{\tau}, \\
& k_{i}^{*}=\bar{k}+\frac{\bar{\tau}-\tau_{i}}{2}, \quad i=L, M, S,
\end{aligned}
$$

where $\bar{\tau} \equiv\left(\tau_{L}+\tau_{M}+\tau_{S}\right) / 3$ is the average capital tax rate of all countries. Differentiating (1) and (2) with respect to $\tau_{i}$ yields, respectively, the following impacts:

$$
\frac{\partial r^{*}}{\partial \tau_{i}}=-\frac{1}{3}<0, \frac{\partial k_{i}^{*}}{\partial \tau_{i}}=-\frac{1}{3}<0, \text { and } \frac{\partial k_{j}^{*}}{\partial \tau_{i}}=\frac{1}{6}>0, \quad i \neq j
$$

An increase in $\tau_{i}$ reduces the net remuneration on capital in country $i, r^{*}$, leading to an outflow of capital. A fall in $r^{*}$ is caused both by the direct reduction in the net remuneration on capital in country $i$ and by the decrease in the marginal productivity of capital in other countries due to the induced inflow of capital.

The representative residents of all countries are identical. They inelastically supply one unit of labor to domestic firms and invest their own capital holdings in the home and foreign countries. They spend their income on the consumption of the numéraire good $c_{i}$. Accordingly, the budget constraint of a household in country $i$ is expressed as $c_{i}=w_{i}+r \bar{k}_{i}$. Taking (1), (2), and the tax rates chosen by the other countries as given, the government of country $i$ chooses $\tau_{i}$ so as to maximize the utility function of its resident: $u_{i}\left(c_{i}, g_{i}\right) \equiv c_{i}+g_{i}=f\left(k_{i}^{*}\right)+r^{*}\left(\bar{k}_{i}-k_{i}^{*}\right) .{ }^{3}$ Together with a quadratic production function, the assumed specification of linear utility allows us to derive a closed-form solution for the equilibrium tax rates associated with the different phases of the repeated

\footnotetext{
${ }^{2}$ We assume $a \geq(24+7 \varepsilon) \bar{k} / 12$ to ensure the non-negative net return on capital throughout the paper.

${ }^{3}$ Introducing the shadow price of public expenditures (the marginal cost of public funds) $\lambda_{i}$; i.e., $u_{i}=c_{i}+\left(1+\lambda_{i}\right) g_{i}$, allows for another efficiency consideration. Keen and Konrad (2013) show that a larger $\lambda_{i}$ enhances the beneficial effect of public expenditure in such a way that substitution from private to public consumption by increasing capital taxes mitigates the race-to-the-bottom competition. However, we omit such an analysis in order to focus on the inefficiency of production associated with the tax differentials in asymmetric tax competition and to obtain clear results.
} 
tax competition game, which is defined later (see also Bucovetsky $(1991,2009)$ and Peralta and van Ypersele (2006)). The first-order condition for country $i$ is as follows:

$$
\frac{\partial u_{i}}{\partial \tau_{i}}=\left[f^{\prime}\left(k_{i}^{*}\right)-r^{*}\right] \frac{\partial k_{i}^{*}}{\partial \tau_{i}}+\left(\bar{k}_{i}-k_{i}^{*}\right) \frac{\partial r^{*}}{\partial \tau_{i}}=0
$$

Substituting (1), (2) and (3) into (4) and rearranging yields the best-response function of country $i$ :

$$
\tau_{i}=\frac{1}{8}\left[\tau_{j}+\tau_{h}+6\left(\bar{k}-\bar{k}_{i}\right)\right], \quad i \neq j \neq h,
$$

which reveals that the tax rates are strategic complements (see Konrad and Schjelderup (1999)). By solving the best-response function (5) for all countries, we obtain the following Nash equilibrium tax rates, denoted by $\tau_{i}^{N}$, in the one-shot tax competition game:

$$
\tau_{L}^{N}=-\frac{2}{3} \varepsilon \bar{k}<0, \quad \tau_{M}^{N}=-\frac{2}{3} \varepsilon \theta \bar{k} \gtreqless 0, \text { and } \tau_{S}^{N}=\frac{2}{3} \varepsilon(1+\theta) \bar{k}>0 .
$$

Recalling that $\bar{\tau}=0$ in the Nash equilibrium and substituting (6) into (1) and (2) yields the following equilibrium net return and the amount of capital demanded in country $i$, respectively:

$$
\begin{aligned}
& r^{N}=a-2 \bar{k} \\
& k_{L}^{N}=\left(1+\frac{1}{3} \varepsilon\right) \bar{k}, \quad k_{M}^{N}=\left(1+\frac{1}{3} \varepsilon \theta\right) \bar{k}, \text { and } k_{S}^{N}=\left[1-\frac{1}{3} \varepsilon(1+\theta)\right] \bar{k}
\end{aligned}
$$

It follows from (6) and (8) that $\bar{k}_{L}-k_{L}^{N}=2 \varepsilon \bar{k} / 3>0, \bar{k}_{M}-k_{M}^{N}=2 \varepsilon \theta \bar{k} / 3 \gtreqless 0$, and $\bar{k}_{S}-k_{S}^{N}=$ $-2 \varepsilon(1+\theta) \bar{k} / 3<0$; that is, country $L$ exports capital with subsidies (i.e., $\tau_{L}^{N}<0$ ), while country $S$ imports capital with taxation (i.e., $\tau_{S}^{N}>0$ ). This result stems from the terms-of-trade effect; i.e., capital importers (exporters) are willing to levy positive (negative) tax rates on capital in order to decrease (increase) capital payments through a reduction (increase) in the price of capital, $r^{*}$, in (1). On the other hand, country $M$ may be either an importer with taxation (i.e., $\tau_{M}^{N}>0$ ) for $\theta \in[-1 / 2,0)$ or an exporter with subsidies (i.e., $\left.\tau_{M}^{N}<0\right)$ for $\theta \in(0,1] .{ }^{4}$ By making use of $(7)$ and

\footnotetext{
${ }^{4}$ Notably, when $\theta=0$, country $M$ sets $\tau_{M}^{N}=0$ because its net trade of capital is equal to zero (i.e., $k_{M}^{N}=\bar{k}_{M}$ ), and thus, country $M$ neither gains nor loses by manipulating $\tau_{M}^{N}$.
} 
(8), we obtain the utility levels of the three countries at the Nash equilibrium:

$$
\begin{aligned}
& u_{L}^{N}=(a-\bar{k}) \bar{k}_{L}-\varepsilon\left(1+\frac{1}{9} \varepsilon\right) \bar{k}^{2}, \\
& u_{M}^{N}=(a-\bar{k}) \bar{k}_{M}-\varepsilon \theta\left(1+\frac{1}{9} \varepsilon \theta\right) \bar{k}^{2}, \\
& u_{S}^{N}=(a-\bar{k}) \bar{k}_{S}+\varepsilon(1+\theta)\left[1-\frac{1}{9} \varepsilon(1+\theta)\right] \bar{k}^{2} .
\end{aligned}
$$

\section{Full Harmonization}

In this section, we construct a simple repeated tax competition game in which all countries possess a common discount factor $\delta \in[0,1)$. We use the terms "coalition" and "union" to refer to any group of countries that agree to implement tax harmonization. Let $G$ represent a subset of countries; i.e., $G \subseteq\{L, M, S\}$. We consider four possible coalitions, excluding a singleton: $G \in$ $\{\{L, M\},\{M, S\},\{L, S\},\{L, M, S\}\}$. We denote, for example, the set $\{L, M\}$ simply by $L M$.

Using these notations, we can express the utility function of country $i$ in phase $P$ as follows:

$$
\begin{aligned}
u_{i}^{P}(G) & \equiv u\left(c_{i}^{P}(G), g_{i}^{P}(G)\right)=c_{i}^{P}(G)+g_{i}^{P}(G) \\
& =f\left(k_{i}^{P}(G)\right)+r_{i}^{P}(G)\left[\bar{k}_{i}-k_{i}^{P}(G)\right], \quad P=C, D,
\end{aligned}
$$

where we index all the endogenous variables pertaining to a tax union $G$ and phase $P(=N, C$ or $D)$, such as $c_{i}^{P}(G), g_{i}^{P}(G)$, and so on.

Assume that in every period, each country belonging to union $G$ sets a common capital tax rate on the condition that the other countries belonging to union $G$ follow it in the previous period. If at least one country deviates from it, then their cooperation collapses, thus triggering the punishment phase that results in the one-shot Nash equilibrium, which persists forever. To sustain cooperation, the following condition for country $i$ belonging to union $G$ must be satisfied:

$$
\frac{1}{1-\delta} u_{i}^{C}(G) \geq u_{i}^{D}(G)+\frac{\delta}{1-\delta} u_{i}^{N}, \quad i \in G
$$

The left-hand side of (12) is the discounted total utility for a representative resident in country $i$ when the tax harmonization supported by union $G$ is infinitely sustained, while its right-hand side represents the sum of the utility resulting from the deviation by setting the best-deviation tax rate in the current period and the total discounted utility resulting from the Nash phase in all following 
periods.

Consider first the full harmonization supported by the grand coalition $G=L M S$, wherein all three countries agree to jointly set the welfare-maximizing capital tax rates. Namely, maximizing the utilitarian social welfare function $W(L M S) \equiv u_{L}+u_{M}+u_{S}=f\left(k_{L}^{*}\right)+f\left(k_{M}^{*}\right)+f\left(k_{S}^{*}\right)$ with respect to $\tau_{i}, i=L, M, S$ in each period yields the following first-order conditions: ${ }^{5}$

$$
\frac{\partial W(L M S)}{\partial \tau_{i}}=f^{\prime}\left(k_{L}^{*}\right) \frac{\partial k_{L}^{*}}{\partial \tau_{i}}+f^{\prime}\left(k_{M}^{*}\right) \frac{\partial k_{M}^{*}}{\partial \tau_{i}}+f^{\prime}\left(k_{S}^{*}\right) \frac{\partial k_{S}^{*}}{\partial \tau_{i}}=0, \quad i=L, M, S .
$$

Solving these equations using (2) and (3) yields the common harmonized tax rate $\tau^{C}\left(=\tau_{L}=\tau_{M}=\right.$ $\tau_{S}$ ), although its level is indeterminate (see also Peralta and van Ypersele (2006) and Itaya et al. (2008)). The first-best outcome can be achieved by any tax level as long as all countries set the same tax rate though the equalization of the marginal productivity of capital in all countries. This, together with the identical production and utility functions, leads to a common tax rate $\tau^{C}$. For notational simplicity, in the case of full harmonization, we drop the notation $G$ from the endogenous variables pertaining to union $G$. Substituting this common tax rate into (1) and (2) yields, respectively, the net return, $r^{C}\left(=r^{N}-\tau^{C}=a-2 \bar{k}-\tau^{C}\right)$, and the same amount of capital demanded, $k^{C}(=\bar{k})$, across all countries. The latter implies that country $L$ becomes a capital exporter (i.e., $\bar{k}_{L}-k^{C}=\varepsilon \bar{k}>0$ ) and that country $S$ becomes a capital importer (i.e., $\bar{k}_{S}-k^{C}=-\varepsilon(1+\theta) \bar{k}<0$ ), while country $M$ is a capital importer when $\theta \in[-1 / 2,0)$, an exporter when $\theta \in(0,1]$, and its net trade of capital is equal to zero at $\theta=0$ (recall $\left.\bar{k}_{M}-k^{C}=\varepsilon \theta \bar{k}\right)$.

The resulting utility levels of the countries, $u_{i}^{C}$, are as follows:

$$
\begin{aligned}
u_{L}^{C} & =(a-\bar{k}) \bar{k}_{L}-\varepsilon\left(\bar{k}+\tau^{C}\right) \bar{k}, \\
u_{M}^{C} & =(a-\bar{k}) \bar{k}_{M}-\varepsilon \theta\left(\bar{k}+\tau^{C}\right) \bar{k}, \\
u_{S}^{C} & =(a-\bar{k}) \bar{k}_{S}+\varepsilon(1+\theta)\left(\bar{k}+\tau^{C}\right) \bar{k} .
\end{aligned}
$$

Although full harmonization entails an indeterminate capital tax rate, the participation constraints for the respective countries, i.e., $u_{i}^{C} \geq u_{i}^{N}$ for $i=L, M, S$ restrict the range of harmonized tax rates.

\footnotetext{
${ }^{5}$ More generally, the social welfare function can be expressed as $W \equiv N_{L} u_{L}+N_{M} u_{M}+N_{S} u_{S}$, which is weighted by the population of each country, $N_{i}$. Nevertheless, the assumption of identical populations allows us to eliminate $N_{i}$, $i=L, M, S$.
} 
The intersection of those constraints are given by

$$
\tau^{C} \in \begin{cases}{[-\varepsilon(1+\theta) \bar{k} / 9, \varepsilon \theta \bar{k} / 9]} & \text { if } \theta \in[0,1] \\ {[\varepsilon \theta \bar{k} / 9, \varepsilon \bar{k} / 9]} & \text { if } \theta \in[-(1 / 2), 0]\end{cases}
$$

It is evident that an increase in $\theta$ or $\varepsilon$ enlarges the above range of harmonized tax rates. To intuitively explain this result, we decompose the effects on the utility difference $u_{i}^{C}-u_{i}^{N}$ for $i=M, S$ in the Nash equilibrium and in the cooperative phase into the capital movement effect, the terms-of-trade effect, and the capital endowment effect. To to this, we differentiate $u_{i}^{P}=f\left(k_{i}^{P}\right)+r^{P}\left(\bar{k}_{i}-k_{i}^{P}\right)$ for $P=N, C$ with respect to $\theta$ and using $r^{P}=f^{\prime}\left(k_{i}^{P}\right)-\tau_{i}^{P}$ to get ${ }^{6}$

$$
\begin{aligned}
\frac{\partial u_{i}^{P}}{\partial \theta} & =\underbrace{\left[f^{\prime}\left(k_{i}^{P}\right)-r^{P}\right] \frac{\partial k_{i}^{P}}{\partial \theta}}_{\text {capital movement effect }}+\underbrace{\left(\bar{k}_{i}-k_{i}^{P}\right) \frac{\partial r^{P}}{\partial \theta}}_{\text {terms-of-trade effect }}+\underbrace{r^{P} \frac{\partial \bar{k}_{i}}{\partial \theta},}_{\text {capital endowment effect }} \\
& =\left\{\begin{array}{c}
\underbrace{\tau_{i}^{N}\left(\partial k_{i}^{N} / \partial \theta\right)}_{\text {capital movement effect }}+\underbrace{r^{N}\left(\partial \bar{k}_{i} / \partial \theta\right)}_{\text {capital endowment effect }}>0 \text { for } i=M,<0 \text { for } i=S, \\
\underbrace{r^{C}\left(\partial \bar{k}_{i} / \partial \theta\right)}_{\text {capital endowment effect }}>0 \text { for } i=M,<0 \text { for } i=S .
\end{array}\right.
\end{aligned}
$$

Given a constant $\varepsilon>0$, an increase in $\theta \in[0,1]$ not only makes the capital endowment of country $M$ closer to that of country $L$ (i.e., the positive capital endowment effect), it also makes that of country $S$ shrink (i.e., the negative capital endowment effect). Since from (7), $r^{N}$ and $r^{C}\left(=r^{N}-\tau^{C}\right)$ do not depend on $\theta$, the terms-of-trade effect does not arise in either phase. The capital movement effect does not emerge in the cooperative phase since there is no tax differential across countries due to a common harmonized tax rate. In contrast, in the Nash equilibrium, capital-exporting country $M$ with more capital stock sets a lower (negative) tax rate, while capital-importing country $S$ with less capital stock sets a higher (positive) tax rate. Although the resulting larger tax differential stimulates capital movement from country $S$ to $M$, the capital movement effects for both countries turn out to be negative (recall that $\tau_{S}^{N}>0$ and $\tau_{M}^{N}<0$ ). The results are summarized in Table 1, which shows that the overall effects on $u_{i}^{N}$ and $u_{i}^{C}, i=M, S$ exhibit the same sign. Nevertheless, because of the presence of the negative capital movement effect in the Nash equilibrium, the utility difference $u_{i}^{C}-u_{i}^{N}$ for $i=M, S$ increases with $\theta$. Similarly, an increase in $\varepsilon$ makes the capital endowments among countries more heterogenous, resulting in a larger tax differential between countries, thereby

\footnotetext{
${ }^{6}$ The precise definitions for the capital movement and terms-of-trade effects are found in Peralta and van Ypersele (2006).
} 
enlarging the utility difference $u_{i}^{C}-u_{i}^{N}, i=M, S$ as before.

\begin{tabular}{|c||c|c|c|c|c|}
\hline & Phase & Capital Movement & Terms-of-Trade & Capital Endowment & Utility \\
\hline \hline \multirow{2}{*}{ Country $M$} & Nash & - & 0 & + & + \\
\cline { 2 - 6 } & Cooperation & 0 & 0 & + & + \\
\hline \hline \multirow{2}{*}{ Country $S$} & Nash & - & 0 & - & - \\
\cline { 2 - 6 } & Cooperation & 0 & 0 & - & - \\
\hline
\end{tabular}

Table 1. Effects of an increase in $\theta$ on the utilities of countries $M$ and $S$ for $\theta \in[0,1]$

To identify the conditions under which the full harmonization satisfying the tax range (16) is sustainable, we calculate the best-deviation tax rate of country $i$, denoted by $\tau_{i}^{D}$, that maximizes $u_{i}$ given that all other countries follow the harmonized tax rate $\tau^{C}$. Setting $\tau_{j}=\tau_{h}=\tau^{C}$ in (5) yields the best-deviation tax rates for each country:

$$
\tau_{L}^{D}=\frac{1}{4}\left(\tau^{C}-3 \varepsilon \bar{k}\right)<0, \tau_{M}^{D}=\frac{1}{4}\left(\tau^{C}-3 \varepsilon \theta \bar{k}\right), \text { and } \tau_{S}^{D}=\frac{1}{4}\left[\tau^{C}+3 \varepsilon(1+\theta) \bar{k}\right]>0
$$

Utilizing (1), (2), and (18), we derive the utility level of the unilateral deviator $i$, denoted by $u_{i}^{D}$, for $i=L, M, S$ as follows:

$$
\begin{aligned}
u_{L}^{D} & =(a-\bar{k}) \bar{k}_{L}+\frac{1}{8}\left[\left(\tau^{C}\right)^{2}-6 \varepsilon \bar{k} \tau^{C}+(\varepsilon-8) \varepsilon \bar{k}^{2}\right] \\
u_{M}^{D} & =(a-\bar{k}) \bar{k}_{M}+\frac{1}{8}\left[\left(\tau^{C}\right)^{2}-6 \varepsilon \theta \theta \bar{k} \tau^{C}+(\varepsilon \theta-8) \varepsilon \theta \bar{k}^{2}\right] \\
u_{S}^{D} & =(a-\bar{k}) \bar{k}_{S}+\frac{1}{8}\left[\left(\tau^{C}\right)^{2}+6 \varepsilon(1+\theta) \bar{k}^{C}+\varepsilon(1+\theta)(8+\varepsilon(1+\theta)) \bar{k}^{2}\right] .
\end{aligned}
$$

Combining the equality in (12) with the corresponding utilities (9)-(11), (13)-(15), and (19)-(21) yields the minimum discount factors of the countries, denoted by $\underline{\delta}_{i}$, for $i=L, M, S$ above which they find it to be in their interest to cooperate, as follows:

$$
\begin{aligned}
\underline{\delta}_{L} & \equiv \frac{u_{L}^{D}-u_{L}^{C}}{u_{L}^{D}-u_{L}^{N}}=\frac{9\left(\varepsilon \bar{k}+\tau^{C}\right)^{2}}{\left(\varepsilon \bar{k}-3 \tau^{C}\right)\left(17 \varepsilon \bar{k}-3 \tau^{C}\right)}, \\
\underline{\delta}_{M} & \equiv \frac{u_{M}^{D}-u_{M}^{C}}{u_{M}^{D}-u_{M}^{N}}=\frac{9\left(\varepsilon \theta \bar{k}+\tau^{C}\right)^{2}}{\left(\varepsilon \theta \bar{k}-3 \tau^{C}\right)\left(17 \varepsilon \theta \bar{k}-3 \tau^{C}\right)}, \\
\underline{\delta}_{S} & \equiv \frac{u_{S}^{D}-u_{S}^{C}}{u_{S}^{D}-u_{S}^{N}}=\frac{9\left[\varepsilon(1+\theta) \bar{k}-\tau^{C}\right]^{2}}{\left[\varepsilon(1+\theta) \bar{k}+3 \tau^{C}\right]\left[17 \varepsilon(1+\theta) \bar{k}+3 \tau^{C}\right]}
\end{aligned}
$$




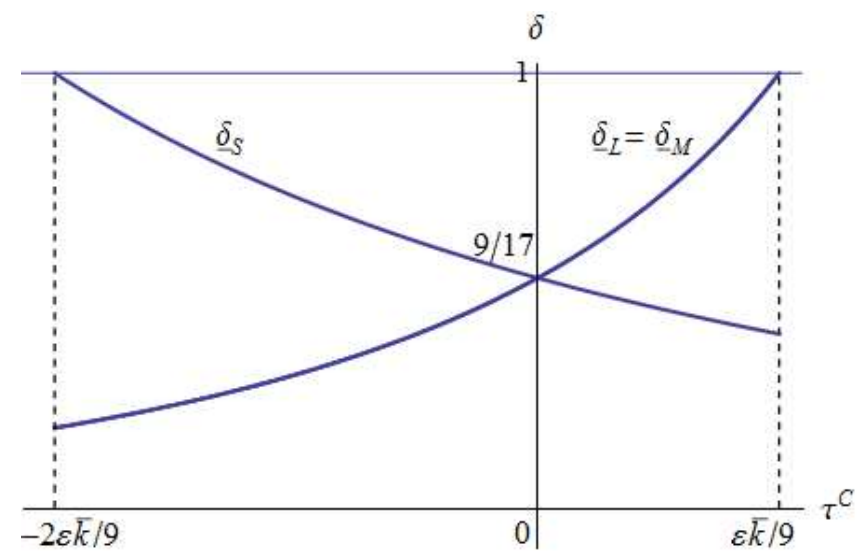

Figure 1: Loci of the minimum discount factors under full harmonization when $\theta=1$.

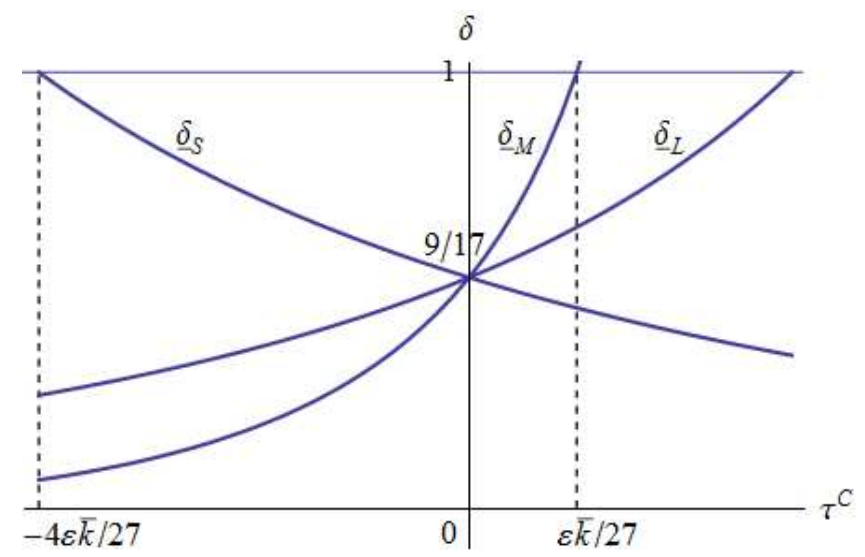

Figure 2: Loci of the minimum discount factors under full harmonization when $\theta=1 / 3$.

Only when the actual (common) discount factor of all three countries, $\delta$, is greater than the threshold value of the discount factor, defined by $\delta^{*} \equiv \max \left[\underline{\delta}_{L}, \underline{\delta}_{M}, \underline{\delta}_{S}\right]$, the harmonized tax rate $\tau^{C}$ can be sustained as a subgame perfect Nash equilibrium of the repeated game. Any harmonized common tax rate $\tau^{C}$ satisfying (16) can realize the first-best allocation of capital by eliminating the tax differentials across countries, while every country's incentive to cooperate is critically influenced by the chosen level of the harmonized tax rate $\tau^{C}$. Indeed, it is straightforward to verify that $\underline{\delta}_{L}$ in (22) is increasing in $\tau^{C}$ and $\underline{\delta}_{S}$ in (24) is decreasing in $\tau^{C}$, while the locus of $\underline{\delta}_{M}$ in (23) crucially hinges on the net exporting position of country $M$; namely, $\underline{\delta}_{M}$ is increasing (decreasing) in $\tau^{C}$ if country $M$ is a capital exporter; i.e., $\theta>0$ (a capital importer; i.e., $\theta<0$ ); see the appendix. Figs.1, 2, 3 , and 4 depict the behavior of the minimum discount factors of all three countries with respect to $\tau^{C}$ for $\theta=1,1 / 3,-1 / 3$, and $-1 / 2$, respectively. Algebraically, it follows from (16) and (22)-(24), together with $\delta^{*}=\max \left[\underline{\delta}_{L}, \underline{\delta}_{M}, \underline{\delta}_{S}\right]$, that the threshold values of the discount factors associated with 


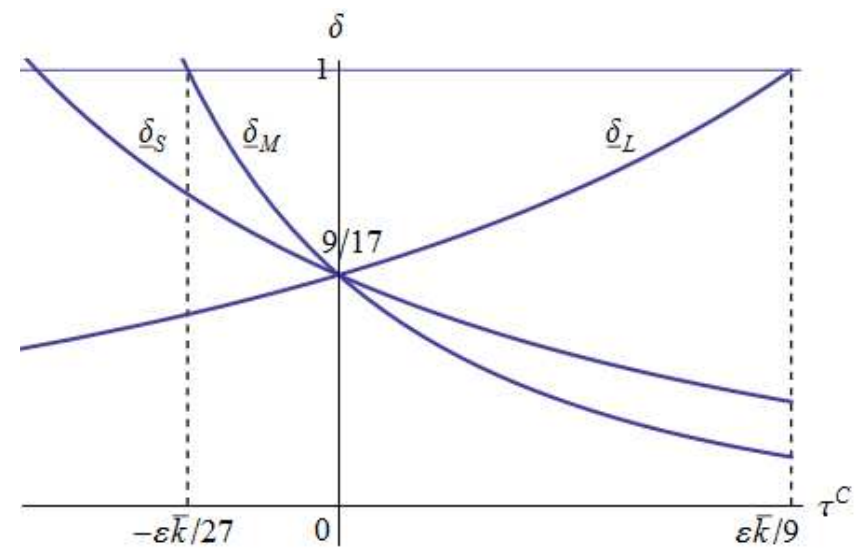

Figure 3: Loci of the minimum discount factors under full harmonization when $\theta=-1 / 3$.

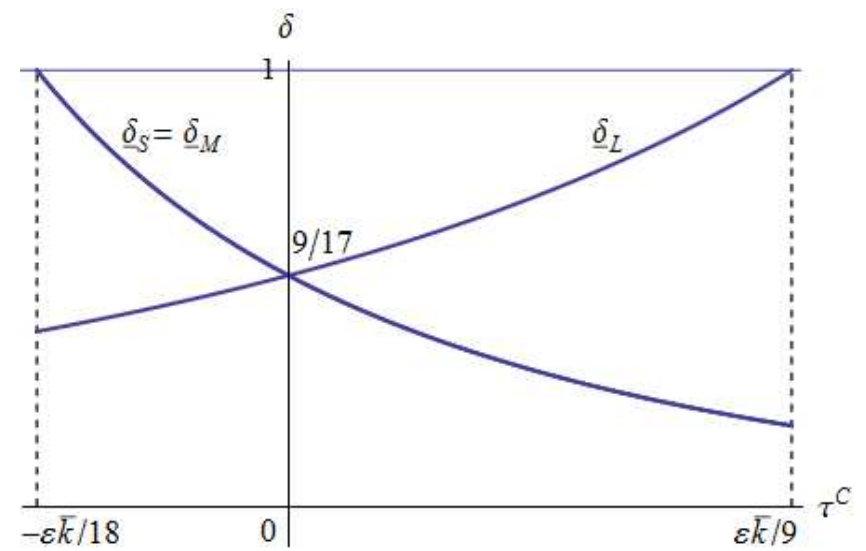

Figure 4: Loci of the minimum discount factors under full harmonization when $\theta=-1 / 2$. 
the different values of $\theta$ are given as follows:

$$
\begin{array}{ll}
\delta^{*}=\left\{\begin{array}{ll}
\underline{\delta}_{S} & \text { for } \tau^{C} \in[-2 \varepsilon \bar{k} / 9,0] \\
\underline{\delta}_{L}=\underline{\delta}_{M} & \text { for } \tau^{C} \in[0, \varepsilon \bar{k} / 9]
\end{array}\right\} & \text { if } \theta=1, \\
\delta^{*}=\left\{\begin{array}{lll}
\underline{\delta}_{S} & \text { for } \tau^{C} \in[-\varepsilon(1+\theta) \bar{k} / 9,0] \\
\underline{\delta}_{M} & \text { for } \tau^{C} \in[0, \varepsilon \theta \bar{k} / 9]
\end{array}\right\} & \text { if } \theta \in(0,1), \\
\delta^{*}=\quad \underline{\delta}_{M}=1 & \text { if } \theta=0, \\
\delta^{*}=\left\{\begin{array}{lll}
\underline{\delta}_{M} & \text { for } & \tau^{C} \in[\varepsilon \theta \bar{k} / 9,0] \\
\underline{\delta}_{L} & \text { for } & \tau^{C} \in[0, \varepsilon \bar{k} / 9]
\end{array}\right\} & \text { if } \theta \in\left(-\frac{1}{2}, 0\right), \\
\delta^{*}=\left\{\begin{array}{ll}
\underline{\delta}_{M}=\underline{\delta}_{S} & \text { for } \tau^{C} \in[-\varepsilon \bar{k} / 18,0] \\
\underline{\delta}_{L} & \text { for } \tau^{C} \in[0, \varepsilon \bar{k} / 9]
\end{array}\right\} & \text { if } \theta=-\frac{1}{2} .
\end{array}
$$

These results are summarized as follows:

Proposition 1 (i) If all countries are sufficiently patient, then full tax harmonization can be sustained as a subgame perfect Nash equilibrium of the repeated tax competition game;

(ii) the harmonized capital tax rate, $\tau^{C}$, is indeterminate. Moreover, if it is positive (negative), then the threshold value of the minimum discount factor that supports full tax harmonization is increasing (decreasing) with $\tau^{C}$; and

(iii) if $\tau^{C}=0$, then the threshold value is the smallest.

The intuition underlying Proposition 1 is as follows. When $\theta \in(0,1]$, countries $L$ and $M$ are both capital exporters, while only country $S$ is a capital importer. When $\tau^{C}>0$, the capital price $r^{C}$ falls by the tax wedge $\tau^{C}>0$ (recalling that $r^{C}=r^{N}-\tau^{C}=a-2 \bar{k}-\tau^{C}>0$ ). In the cooperative phase, there remains only the terms-of-trade effect because there is neither tax differentials across countries nor the capital endowment effect:

$$
\begin{aligned}
\frac{\partial u_{i}^{C}}{\partial \tau^{C}} & =\underbrace{\underbrace{C} \frac{\partial k_{i}^{C}}{\partial \tau^{C}}}_{\text {capital movement effect (0) }}+\underbrace{\left(\bar{k}_{i}-k_{i}^{C}\right) \frac{\partial r^{C}}{\partial \tau^{C}}}_{\text {terms-of-trade effect }}+\underbrace{r^{C} \frac{\partial \bar{k}_{i}}{\partial \tau^{C}}}_{\text {capital endowment effect (0) }} \\
& =\underbrace{-\left(\bar{k}_{i}-k_{i}^{C}\right)}_{\text {terms-of-trade effect }}<0 \text { for } i=L,<0 \text { for } i=M \text {, and }>0 \text { for } i=S
\end{aligned}
$$

In short, an increase in $\tau^{C}$ generates income transfers from the exporters (i.e., countries $L$ and $M$ ) to the importer (i.e., country $S$ ) due to the perverse terms-of-trade effect against the exporters. Such income transfers depress the utilities of capital exporters in the cooperative as well as deviation phases, i.e., $u_{i}^{C}$ and $u_{i}^{D}$, for $i=L, M$. To intuitively explain the reduction of $u_{i}^{D}$ for $i=L$, $M$, we 
decompose the effect into the following two:

$$
\begin{aligned}
\frac{\partial u_{i}^{D}}{\partial \tau^{C}} & =\underbrace{\tau^{C} \frac{\partial k_{i}^{D}}{\partial \tau^{C}}}_{\text {capital movement effect (+) }}+\underbrace{\left(\bar{k}_{i}-k_{i}^{C}\right) \frac{\partial r_{i}^{D}}{\partial \tau^{C}}}_{\text {terms-of-trade effect }(-)}, i=L, M . \\
& =\left\{\begin{array}{l}
\left(\tau^{C}-3 \varepsilon \bar{k}\right) / 4<0 \text { for } L, \\
\left(\tau^{C}-3 \varepsilon \theta \bar{k}\right) / 4<0 \text { for } M,
\end{array}\right.
\end{aligned}
$$

where the negative signs of both expressions in (26) follow from (16). Since it follows from (18) that an increase in $\tau^{C}$ raises $\tau_{i}^{D}$ for $i=L, M$, this increase lowers the capital price $r_{i}^{D}$ in (1). As a result, the terms-of-trade effect is negative for the exporters. In addition, it also turns out from (18) that the tax differential becomes larger $\left(\tau^{C}>\tau_{i}^{D}\right)$, thereby creating capital movement from the tax union to a deviating country. Although these two effects operate in opposite directions, the negative sign of the overall effects on the utilities of both countries in (26) implies that the terms-of-trade effect dominates.

To see how a higher $\tau^{C}$ affects the sustainability of cooperation, we rewrite the sustainability condition (12) as follows:

$$
\frac{\delta}{1-\delta}\left(u_{i}^{C}-u_{i}^{N}\right) \geq u_{i}^{D}-u_{i}^{C}, \quad i=L, M, S
$$

which says that the discounted future losses inflicted by the punishment (i.e., the opportunity cost from deviation) on the left-hand side should be greater than the immediate gain from deviation on the right-hand side. Since $u_{i}^{N}$ is independent of $\tau^{C}$ while $u_{i}^{C}$ decreases with $\tau^{C}$ for $i=L, M$, a higher $\tau^{C}$ unambiguously reduces the opportunity cost from deviation (i.e., $u_{i}^{C}-u_{i}^{N}$ ). Since it can be verified that the immediate gain (i.e., $u_{i}^{D}-u_{i}^{C}$ ) also increases, the minimum discount factor unambiguously rises so that the incentives of the exporters (i.e., countries $L$ and $M$ ) to cooperate will be discouraged by the increase in $\tau^{C}$ (see also (A1) and (A2) in the appendix). The main driving force behind this is that the decrease in $u_{i}^{C}$ not only reduces the opportunity cost of deviation but also increases its benefit. More noteworthy is that the incentive of country $M$ to deviate is stronger than that of country $L$ as long as $\theta \in(0,1]$, which makes the locus of the minimum discount factor $\underline{\delta}_{M}$ steeper than that of $\underline{\delta}_{L}$ for $\tau^{C}>0$, as illustrated in Figs.1 and 2 (the detailed proof is given in the appendix). Intuitively, with the common cooperative tax rate, the gain of country $L$ from eliminating the production inefficiency associated with the tax differentials is larger than that of 
country $M$ because capital-exporting country $L$ exports more capital than country $M$.

In contrast, since a negative harmonized tax rate (i.e., $\tau^{C}<0$ ) harms capital importer $S$ as a result of the higher capital payment $r^{C}$ compared to $r^{N}$ in (7) (i.e., the perverse terms-of-trade effect for country $S$ ), this gives rise to income transfers from capital-importing country $S$ to capitalexporting countries $L$ and $M$, thus strengthening the incentive of country $S$ to deviate. As a result, $\delta^{*}=\underline{\delta}_{S}$ for $\tau^{C}<0$, as shown in Figs.1 and 2.

On the other hand, if $\theta \in[-1 / 2,0)$, then country $L$ is the only capital exporter and countries $M$ and $S$ are both capital importers. By the same reasoning as before, capital-exporting country $L$ has the strongest motivation to deviate for $\tau^{C}>0$; i.e., $\delta^{*}=\underline{\delta}_{L}$, while capital-exporting country $M$ has the strongest motivation to deviate; i.e., $\delta^{*}=\underline{\delta}_{M}$ for $\tau^{C}<0$. These results are illustrated in Figs.3 and 4 .

If $\theta=0$, then country $M$ 's net trade of capital is zero (i.e., $\bar{k}_{M}=k_{M}^{N}=k^{C}=\bar{k}$ ), while countries $L$ and $S$ are still assigned to a capital exporter and an importer, respectively. In this case, since there is no gain from tax coordination due to the absence of capital trade; i.e., $u_{M}^{C}=u_{M}^{N}=f(\bar{k})$, we obtain $\underline{\delta}_{M}=1$ irrespective of any value of $\tau^{C}$. This implies that $\delta^{*}=1$, that is, it is almost surely impossible to sustain full tax harmonization since the actual discount factor cannot exceed one.

Next, we investigate how varying the distribution of capital endowments (i.e., $\varepsilon$ or $\theta$ ) affects the sustainability of full tax harmonization. It follows from (A.5) and (A.6) in the appendix that for given values of $\tau^{C}$ and $\varepsilon$, an increase in $\theta$ makes a counter-clockwise turn of the locus $\underline{\delta}_{S}$ while making a clockwise turn of the locus $\underline{\delta}_{M}$ around the intersection point $(0,9 / 17)$, as illustrated in Figs. 1-4. These figures show that, except for the intersection point, $\delta^{*}\left(=\max \left[\underline{\delta}_{L}, \underline{\delta}_{S}, \underline{\delta}_{M}\right]\right)$ becomes larger as $\theta$ approaches 0 from either direction. This is because the closer the capital endowment of country $M$ is to the average capital endowment, the less the amount of capital trade and the less the gain of country $M$ from eliminating production inefficiency, which makes full harmonization more difficult.

On the other hand, an increase in $\varepsilon$ makes a clockwise turn of the locus $\underline{\delta}_{L}$ and a counter-clockwise turn of the locus $\underline{\delta}_{S}$, while rotating the locus $\underline{\delta}_{M}$ toward the outside around the intersection point (see also (A7), (A8), and (A9) in the appendix). These movements together imply that the sustainable tax range, which coincides with (16), will be widened. It follows from that the increased heterogeneity of capital measured by $\varepsilon$ makes the Nash competition more severe thus enlarging the tax differentials, which ends up enhancing the improvement of production efficiency under full tax harmonization. To sum up, we have: 
Proposition 2 (i) For given values of $\tau^{C} \neq 0$ satisfying (16) and $\varepsilon$, the closer the capital endowment of the median country $\bar{k}_{M}$ is to the average one, the more narrow the range for full tax harmonization is. Conversely, the closer $\bar{k}_{M}$ is to the capital endowment of the large or small country, $\bar{k}_{L}$ or $\bar{k}_{S}$ (i.e., the more skewed the distribution of capital endowments is), the wider the range for full tax harmonization to prevail. When $\bar{k}_{M}$ coincides with the average one, full tax harmonization is almost impossible;

(ii) for given values of $\tau^{C} \neq 0$ satisfying (16) and $\theta \neq 0$, an increase in $\varepsilon$ enlarges the range for full tax harmonization; and

(iii) if $\tau^{C}=0$, then the willingness of every country to sustain full tax harmonization is not only unaffected by the changes in $\varepsilon$ and $\theta$, but it also becomes the strongest.

Proposition 2 implies that the sustainability of full harmonization depends on the degree of asymmetry, which is measured by $\varepsilon$ and $\theta$, and the level of the harmonized tax rate $\tau^{C}$. The point is that the increased asymmetries enlarge the tax differentials across countries, thus intensifying the one-shot Nash equilibrium competition. The gains from tax harmonization, which arise from eliminating production inefficiency caused by the tax differentials, become larger. The increased gains accrued to union member countries make it easier for tax harmonization to be sustained.

Furthermore, adding one country to a two-country model brings about new implications for how asymmetry affects the sustainability of tax harmonization. Notably, if the capital endowment of the median country is less skewed (i.e., if it is closer to the average capital endowment), tax harmonization is less likely to prevail. In other words, there always exists a range of $\tau^{C}$ (i.e., an interval of positive length) in which the median country has the strongest incentive to deviate, as seen in Figs.1-4. This result stands in sharp contrast to Cardarelli et al. (2002) and Catenaro and Vidal (2006) who, using a two-country model, find that the small country has a stronger incentive to deviate from tax harmonization, whereas in our three-country model, the median country has the strongest incentive to deviate in most cases. The reason for this difference is that the halfway position of the net capital trade of the medium country makes the gain from tax coordination smaller compared to those of the partners located at the extreme ends of the capital endowment, which makes tax harmonization less attractive to the medium country. 


\section{Partial Harmonization}

In this section, we investigate the conditions under which partial tax harmonization is sustained. In what follows, we suppose that a subset of any two countries $i, j \in G$ agrees to cooperate on the setting of its common tax rate, while the outside country $h \notin G$ chooses its tax rate noncooperatively. Hence, there are three possible partial tax unions $L M, M S$, and $L S$, wherein tax harmonization is implemented. The tax union $G$ maximizes the sum of their utilities represented by $W(G) \equiv u_{i}+u_{j}=$ $f\left(k_{i}^{*}\right)+f\left(k_{j}^{*}\right)+r^{*}\left(k_{h}^{*}-\bar{k}_{h}\right)$. The first-order condition with respect to $\tau_{i}$ is

$$
\frac{\partial W(G)}{\partial \tau_{i}}=f^{\prime}\left(k_{i}^{*}\right) \frac{\partial k_{i}^{*}}{\partial \tau_{i}}+f^{\prime}\left(k_{j}^{*}\right) \frac{\partial k_{j}^{*}}{\partial \tau_{i}}+r^{*} \frac{\partial k_{h}^{*}}{\partial \tau_{i}}+\frac{\partial r^{*}}{\partial \tau_{i}}\left(k_{h}^{*}-\bar{k}_{h}\right)=0, \quad i, j \in G, \quad i \neq j, \quad h \notin G .
$$

Substituting (1), (2), and (3) into the above condition and rearranging yields the best-response function of a tax union member $i$ as follows:

$$
\tau_{i}=\frac{2}{7}\left[\tau_{j}+\tau_{h}+3\left(\bar{k}_{h}-\bar{k}\right)\right], \quad i, j \in G, \quad i \neq j, \quad h \notin G,
$$

whose symmetry forms lead to $\tau_{i}=\tau_{j}$, i.e., the harmonized capital tax rate should be equalized within the tax union. On the other hand, since outside country $h$ chooses its tax rate so as to maximize its own utility noncooperatively and independently, it behaves according to (5) with $i$ being exchanged for $h$. By solving these best-response functions simultaneously, we obtain the harmonized tax rate set by a partial tax union $G$, denoted by $\tau^{C}(G)$, adopted by the tax union, and the tax rate chosen by the non-member country $h, \tau_{h}^{C}(G)$, in the subgroup Nash equilibrium (see Konrad and Schjelderup, 1999):

$$
\tau^{C}(G)=\bar{k}_{h}-\bar{k} \text { and } \tau_{h}^{C}(G)=-\frac{1}{2}\left(\bar{k}_{h}-\bar{k}\right)
$$

It is important to note that the harmonized tax rate is uniquely determined according to the capital endowments. This uniqueness property stems from the fact that the harmonized tax rate is chosen by solving the best-response functions of the tax union and the outside country, which does not show up in the case of full tax harmonization. Substituting (27) into (1) and (2) yields the following equilibrium net return, $r^{C}(G)$, and the amounts of capital demanded in country $i \in G$ and $h \notin G$, 
denoted by $k_{i}^{C}(G)$ and $k_{h}^{C}(G)$, respectively, in the cooperative phase:

$$
\begin{aligned}
& r^{C}(G)=a-2 \bar{k}-\frac{1}{2}\left(\bar{k}_{h}-\bar{k}\right), \\
& k_{i}^{C}(G)=\bar{k}-\frac{1}{4}\left(\bar{k}_{h}-\bar{k}\right) \text { and } k_{h}^{C}(G)=\bar{k}+\frac{1}{2}\left(\bar{k}_{h}-\bar{k}\right) .
\end{aligned}
$$

The resulting utility levels of the member and non-member countries, denoted by $u_{i}^{C}(G)$ and $u_{h}^{C}(G)$, respectively, are given as follows:

$$
\begin{aligned}
u_{i}^{C}(G) & =(a-\bar{k}) \bar{k}_{i}+\frac{1}{16}\left[\left(\bar{k}+3 \bar{k}_{h}\right)\left(5 \bar{k}-\bar{k}_{h}\right)-8 \bar{k}_{i}\left(\bar{k}+\bar{k}_{h}\right)\right] \\
u_{h}^{C}(G) & =(a-\bar{k}) \bar{k}_{h}+\frac{1}{2}\left(\bar{k}-\bar{k}_{h}\right)\left(\bar{k}+\bar{k}_{h}\right)
\end{aligned}
$$

Condition $u_{i}^{C}(G) \geq u_{i}^{N}$ for country $i$ is required to have an incentive to participate in the tax union $G$. On the other hand, the best-deviation tax rate of member country $i$ is chosen by maximizing $u_{i}$ given that the other member country $j$ follows $\tau^{C}(G)$, which is obtained from setting $\tau_{j}^{C}=\tau^{C}(G)$, $j \neq i$, and $\tau_{h}=\tau_{h}^{C}(G)$ in $(5)$ :

$$
\tau_{i}^{D}(G)=\frac{1}{16}\left[11\left(\bar{k}-\bar{k}_{i}\right)+\left(\bar{k}_{h}-\bar{k}_{i}\right)\right]
$$

Substituting (27) and (32) into (1) and (2) yields:

$$
\begin{aligned}
& r_{i}^{D}(G)=a-2 \bar{k}-\frac{1}{16}\left[\left(\bar{k}-\bar{k}_{i}\right)+3\left(\bar{k}_{h}-\bar{k}_{i}\right)\right] \\
& k_{i}^{D}(G)=\bar{k}+\frac{1}{16}\left[\left(\bar{k}_{h}-\bar{k}_{i}\right)-5\left(\bar{k}-\bar{k}_{i}\right)\right] .
\end{aligned}
$$

From (33) and (34), we obtain the utility of deviating country $i$, denoted by $u_{i}^{D}(G)$, as follows:

$$
u_{i}^{D}(G)=(a-\bar{k}) \bar{k}_{i}+\frac{1}{128}\left[\left(\bar{k}-\bar{k}_{h}\right)^{2}+8\left(\bar{k}-\bar{k}_{i}\right)\left(15 \bar{k}+3 \bar{k}_{h}-2 \bar{k}_{i}\right)\right] .
$$

\subsection{Partial Harmonization between Similar Countries}

First, consider the tax union consisting of countries $L$ and $M$ with country $S$ outside the tax union. In this case, it turns out from (27) that the member countries $L$ and $M$ agree to export capital with subsidies (i.e., $\tau^{C}(L M)<0$ ), while country $S$ imports capital with taxes (i.e., $\tau_{S}^{C}(L M)>0$ ). In other words, the sign of the tax chosen by country $S$ is the inverse of the sign of the harmonized tax rate chosen by the tax union. This is because their net exporting positions of capital are opposed to 
each other. From (9), (10), and (30), we obtain the following participation constraints:

$$
\begin{aligned}
& u_{L}^{C}(L M)-u_{L}^{N}=\frac{1}{144} \varepsilon^{2}\left(61+18 \theta-27 \theta^{2}\right) \bar{k}^{2}>0 \text { for } \theta \in\left[-\frac{1}{2}, 1\right], \\
& u_{M}^{C}(L M)-u_{M}^{N}=\frac{1}{144} \varepsilon^{2}\left(61 \theta^{2}+18 \theta-27\right) \bar{k}^{2} \geq 0 \text { for } \theta \in\left[\frac{3}{61}(8 \sqrt{3}-3), 1\right] .
\end{aligned}
$$

That is, country $L$ always has an incentive to join the tax union for any value of $\theta$, while country $M$ does only if $\theta>3(8 \sqrt{3}-3) / 61 \approx 0.534$, i.e., country $M$ is a capital exporter. The reason for this difference is as follows. If country $M$ were a capital importer, the negative coordinated tax rate $\tau^{C}(L M)$ set by the capital-exporting tax union damages capital-importing country $M$ through the higher capital payment $r^{C}(M S)$. This discourages country $M$ 's incentive to participate.

From (9), (10), (12), (30), and (35), we obtain the minimum discount factors of the member countries $L$ and $M$ as follows:

$$
\begin{gathered}
\underline{\delta}_{L}(L M)=\frac{u_{L}^{D}(L M)-u_{L}^{C}(L M)}{u_{L}^{D}(L M)-u_{L}^{N}}=\frac{9(1+5 \theta)^{2}}{(7+3 \theta)(71+3 \theta)}, \\
\underline{\delta}_{M}(L M)=\frac{u_{M}^{D}(L M)-u_{M}^{C}(L M)}{u_{M}^{D}(L M)-u_{M}^{N}}=\frac{9(5+\theta)^{2}}{(3+7 \theta)(3+71 \theta)} .
\end{gathered}
$$

As seen from (37) and (38), as long as $\theta$ satisfies the participation constraint (36), the partial tax harmonization between countries $L$ and $M$ is sustainable because there exists a range of $\theta$ (i.e., the interval of positive length $\left(\theta_{L M}, 1\right]$ in Fig.5 where $\left.\theta_{L M} \equiv 3(8 \sqrt{3}-3) / 61 \approx 0.534\right)$ such that $\underline{\delta}_{i}(L M)<1, i=L, M$. Moreover, it is straightforward to show that for $\theta \in\left(\theta_{L M}, 1\right], \underline{\delta}_{L}(L M)$ is increasing in $\theta, \underline{\delta}_{M}(L M)$ is decreasing in $\theta$, and $\underline{\delta}_{L}(L M)=\underline{\delta}_{M}(L M)=81 / 185 \approx 0.438$ holds at $\theta=1$, as illustrated in Fig.5.

Next, consider the tax union consisting of countries $M$ and $S$. According to (27), non-member country $L$ exports capital with subsidies (i.e., $\tau_{L}^{C}(M S)<0$ ), while member countries $M$ and $S$ agree to import capital with taxation (i.e., $\tau^{C}(M S)>0$ ). From (10), (11), and (30), their incentives to participate in the tax union can be described as follows:

$$
\begin{aligned}
& u_{M}^{C}(M S)-u_{M}^{N}=\frac{1}{144} \varepsilon^{2}\left(16 \theta^{2}-72 \theta-27\right) \bar{k}^{2} \geq 0 \text { for } \theta \in\left[-\frac{1}{2}, \frac{3}{4}(3-2 \sqrt{3})\right], \\
& u_{S}^{C}(M S)-u_{S}^{N}=\frac{1}{144} \varepsilon^{2}\left(16 \theta^{2}+104 \theta+61\right) \bar{k}^{2}>0 \text { for } \theta \in\left[-\frac{1}{2}, 1\right],
\end{aligned}
$$

which reveals that although country $S$ is willing to join the tax union at any value of $\theta$, country $M$ 


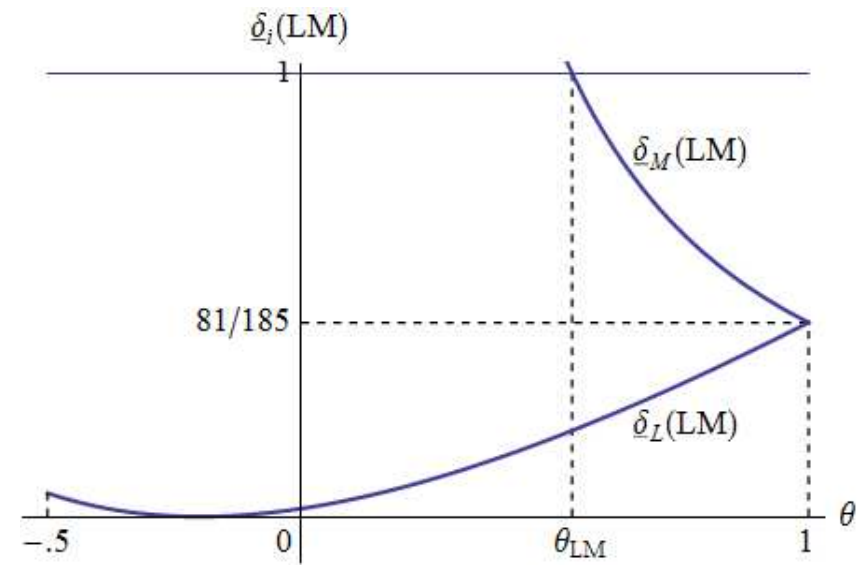

Figure 5: Loci of the minimum discount factors of countries $L$ and $M$.

can join it only when country $M$ is a capital importer (i.e., if $\theta<3(3-2 \sqrt{3}) / 4 \approx-0.348$ ). If country $M$ were a capital exporter, the positive coordinated tax $\tau^{C}(M S)$ set by the capital-importing tax union damages country $M$ because of the lower capital payment $r^{C}(M S)$. This discourages country $M$ 's incentive to participate.

Utilizing (10), (11), (12), (30), and (35), we obtain the minimum discount factors of member countries $M$ and $S$ as follows:

$$
\begin{aligned}
\underline{\delta}_{M}(M S) & =\frac{u_{M}^{D}(M S)-u_{M}^{C}(M S)}{u_{M}^{D}(M S)-u_{M}^{N}}=\frac{9(5+4 \theta)^{2}}{(3-4 \theta)(3-68 \theta)}, \\
\underline{\delta}_{S}(M S) & =\frac{u_{S}^{D}(M S)-u_{S}^{C}(M S)}{u_{S}^{D}(M S)-u_{S}^{N}}=\frac{9(1-4 \theta)^{2}}{(7+4 \theta)(71+68 \theta)} .
\end{aligned}
$$

As long as the capital endowment of country $M$ is close to that of country $S$ (i.e., $\theta<\theta_{M S} \equiv$ $3(3-2 \sqrt{3}) / 4 \approx-0.348)$, partial harmonization between $M$ and $S$ is sustainable, i.e., there exists a range of $\theta$ (i.e., the interval of positive length $\left[-1 / 2, \theta_{M S}\right)$ in Fig.6) such that $\underline{\delta}_{i}(M S)<1, i=M, S$. Furthermore, we can show that within the interval $\left[-1 / 2, \theta_{M S}\right), \underline{\delta}_{M}(M S)$ is increasing in $\theta, \underline{\delta}_{S}(M S)$ is decreasing in $\theta$, and they intersect each other at $\theta=-1 / 2$, as illustrated in Fig.6.

These observations lead to the following proposition:

Proposition 3 (i) If two countries with similar capital endowments (i.e., countries $L$ and $M$ for $\theta \in$ $\left(\theta_{L M}, 1\right]$ or $M$ and $S$ for $\left.\theta \in\left[-1 / 2, \theta_{M S}\right)\right)$ are sufficiently patient, then their partial tax harmonization with a uniquely determined harmonized tax rate can be sustained as a subgame perfect Nash equilibrium of the repeated tax competition game;

(ii) as the capital endowment of country $M$ approaches that of its partner (i.e., $\theta \rightarrow 1$ for $\theta \in\left(\theta_{L M}, 1\right]$ 


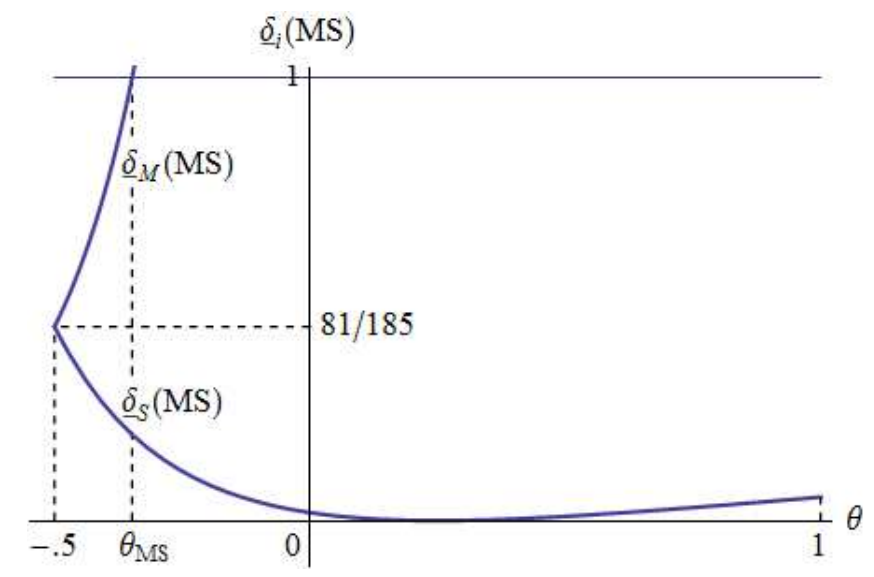

Figure 6: Loci of the minimum discount factors of countries $M$ and $S$.

or $\theta \rightarrow-1 / 2$ for $\theta \in\left[-1 / 2, \theta_{M S}\right)$ ), it becomes easier for partial tax harmonization to prevail, whereas as that of country $M$ approaches the average one (i.e., $\theta \rightarrow 0$ ), the reverse is true; and (iii) the sustainability of partial tax harmonization is independent of $\varepsilon$.

Suppose that $\theta$ increases over the interval $\left(\theta_{L M}, 1\right]$ (see Fig.5). In this case, the capital-exporting tax union which sets a negative harmonized tax rate $\tau^{C}(L M)$ has market power to influence the capital price. As a result, from (28), the higher capital price caused by a larger $\theta,{ }^{C}(L M)=$ $r^{N}+\varepsilon(1+\theta) \bar{k} / 2$, prevails in the equilibrium. This higher remuneration creates the positive termsof-trade effect as well as the negative capital movement effect for the capital-exporting countries. From (30) and given that the capital endowment effect emerges in country $M$ but not in country $L$, we can show that the overall effects on $u_{i}^{C}(L M), i=L, M$ are:

$$
\begin{aligned}
\frac{\partial u_{L}^{C}(L M)}{\partial \theta} & =\underbrace{\tau^{C}(L M) \frac{\partial k_{L}^{C}(L M)}{\partial \theta}}_{\text {capital movement effect (-) }}+\underbrace{\left[\bar{k}_{L}-k_{L}^{C}(L M)\right] \frac{\partial r^{C}(L M)}{\partial \theta}}_{\text {terms-of-trade effect }(+)}=\frac{1}{8} \varepsilon^{2}(1-3 \theta) \bar{k}^{2}<0, \\
\frac{\partial u_{M}^{C}(L M)}{\partial \theta} & =\underbrace{\tau^{C}(L M) \frac{\partial k_{L}^{C}(L M)}{\partial \theta}}_{\text {capital movement effect (-) }}+\underbrace{\left[\bar{k}_{M}-k_{M}^{C}(L M)\right] \frac{\partial r^{C}(L M)}{\partial \theta}}_{\text {terms-of-trade effect (+) }}+\underbrace{r^{C} \frac{\partial \bar{k}_{M}}{\partial \theta}}_{\text {capital endowment effect (+) }} \\
& =\varepsilon\left[a-2 \bar{k}+\frac{1}{8} \varepsilon(1+5 \theta) \bar{k}\right] \bar{k}>0 .
\end{aligned}
$$

The opposite signs above stem mainly from not only the fact that there is the positive endowment effect for country $M$ but not for country $L$, but also the one that there is the terms-of-trade effect in the cooperative phase, unlike in full harmonization. For the reason stated in the previous section, moreover, the effect on $u_{i}^{C}(L M)$ has a dominant role in determining the minimum discount factor of 
member countries, so the minimum discount factor of country $L$ in (37) increases with $\theta$, while that of country $M$ in (38) decreases with $\theta$, as illustrated in Fig.5.

On the other hand, consider the case of $\theta$ increasing over the interval $\left[-1 / 2, \theta_{M S}\right)$ in Fig.6. A change in $\theta$ affects neither the total capital endowment of the tax union consisting of countries $M$ and $S$ nor that of outside country $L$. As a result, neither has an incentive to change the capital tax rate $\tau^{C}(M S)$; thus, the capital price (i.e., $\left.r^{C}(M S)=r^{N}-\varepsilon \bar{k} / 2\right)$ remains unchanged. Hence, neither the terms-of-trade effect nor the capital movement effect operates, and thus the only capital endowment effect remains, which is positive for country $M$ but negative for country $S$. That is,

$$
\begin{aligned}
\frac{\partial u_{M}^{C}(M S)}{\partial \theta} & =\varepsilon\left(a-2 \bar{k}-\frac{1}{2} \varepsilon \bar{k}\right) \bar{k}>0, \\
\frac{\partial u_{S}^{C}(M S)}{\partial \theta} & =-\varepsilon\left(a-2 \bar{k}-\frac{1}{2} \varepsilon \bar{k}\right) \bar{k}<0 .
\end{aligned}
$$

These opposite signs, together with $\partial u_{M}^{N} / \partial \theta<0$ and $\partial u_{S}^{N} / \partial \theta>0$, imply that the increase in $\theta$ (i.e., the decrease in the absolute value of $\theta<0$ ) favors country $M$ less since the gain from partial harmonization for country $M$ decreases; thus, the incentive for country $M$ to cooperate is discouraged, whereas the reverse is true for country $S$.

\subsection{Partial Harmonization between Dissimilar Countries}

Finally, consider the tax union consisting of countries $L$ and $S$. In this case, whether the harmonized common tax rate $\tau^{C}(L S)$ is positive or negative crucially depends on the sign of $\theta$, as seen from (27). This is because whether the total capital endowment of the tax union (i.e., $\bar{k}_{L}+\bar{k}_{S}=(2-\varepsilon \theta) \bar{k}$ ) exceeds or falls short of their capital demands (i.e., $k_{L}^{C}(L S)+k_{S}^{C}(L S)=(2-\varepsilon \theta / 2) \bar{k}$ ) depends on whether outside country $M$ is richer (i.e., $\theta>0$ ) or poorer (i.e., $\theta<0$ ). If $\theta \in[-1 / 2,0$ ), the union exports more capital to country $M$. In this case, the capital-exporting union is willing to choose a negative harmonized tax rate (i.e., subsidies), while the reverse is true if $\theta \in(0,1]$. By the same token, outside country $M$ becomes a capital importer with taxation (i.e., $\tau_{M}^{C}(L S)>0$ ) if $\theta \in[-1 / 2,0$ ), or an exporter with subsidies (i.e., $\left.\tau_{M}^{C}(L S)<0\right)$ if $\theta \in(0,1]$.

From (9), (11), and (30), we obtain the participation constraint for member countries $L$ and $S$ 
as follows:

$$
\begin{aligned}
& u_{L}^{C}(L S)-u_{L}^{N}=\frac{1}{144} \varepsilon^{2}\left(16-72 \theta-27 \theta^{2}\right) \bar{k}^{2} \geq 0 \text { for } \theta \in\left[-\frac{1}{2}, \frac{4}{9}(2 \sqrt{3}-3)\right], \\
& u_{S}^{C}(L S)-u_{S}^{N}=\frac{1}{144} \varepsilon^{2}\left(16+104 \theta+61 \theta^{2}\right) \bar{k}^{2} \geq 0 \text { for } \theta \in\left[\frac{4}{61}(6 \sqrt{3}-13), 1\right] .
\end{aligned}
$$

Country $S$ is willing to join the tax union when $\theta>4(6 \sqrt{3}-13) / 61 \approx-0.171$, while country $L$ does only when $\theta<4(2 \sqrt{3}-3) / 9 \approx 0.206$. Intuitively, when country $M$ is too rich (i.e., a sufficiently large $\theta>0.206)$, country $L$ never wants to join the tax union because the tax union is enforced to import a larger amount of capital and thus has to set a higher positive tax rate, whereas capital-exporting country $L$ always prefers a negative one. In contrast, when country $M$ is too poor (i.e., a sufficiently small $\theta<-0.171$ ), a lower negative tax rate imposed on the capital-exporting tax union prevents capital-importing country $S$ from participating in the union.

From (9), (11), (12), (30), and (35), we obtain the minimum discount factors of countries $L$ and $S$ in the tax union as follows:

$$
\begin{aligned}
& \underline{\delta}_{L}(L S)=\frac{u_{L}^{D}(L S)-u_{L}^{C}(L S)}{u_{L}^{D}(L S)-u_{L}^{N}}=\frac{9(4+5 \theta)^{2}}{(4-3 \theta)(68-3 \theta)} \\
& \underline{\delta}_{S}(L S)=\frac{u_{S}^{D}(L S)-u_{S}^{C}(L S)}{u_{S}^{D}(L S)-u_{S}^{N}}=\frac{9(4-\theta)^{2}}{(4+7 \theta)(68+71 \theta)} .
\end{aligned}
$$

As long as country $M$ is not too skewed (i.e., $\theta$ satisfies the participation constraints (42) and (43)), partial harmonization between $L$ and $S$ is sustainable; that is, there exists a range of $\theta$ (i.e., the interval of positive length $\left(\theta_{L S}^{\min }, \theta_{L S}^{\max }\right)$ in Fig.7 where $\theta_{L S}^{\min } \equiv 4(6 \sqrt{3}-13) / 61 \approx-0.171$ and $\left.\theta_{L S}^{\max } \equiv 4(2 \sqrt{3}-3) / 9 \approx 0.206\right)$ such that $\underline{\delta}_{i}(L S)<1, i=L, S$. Further, we can show that $\underline{\delta}_{L}(L S)$ is increasing in $\theta$, while $\underline{\delta}_{S}(L S)$ is decreasing in $\theta$, and that the loci of these minimum discount factors intersect when $\theta=0$; see Fig.7. These observations lead to the conclusion that partial harmonization is sustainable when the actual (common) discount factor $\delta$ of the member countries is greater than $\underline{\delta}_{S}(L S)$ for $\theta \in\left(\theta_{L S}^{\min }, 0\right)$ and $\underline{\delta}_{L}(L S)$ for $\theta \in\left(0, \theta_{L S}^{\max }\right)$. Hence, we can obtain the results similar to Proposition 3 except for the sustainable range of $\theta \in\left(\theta_{L S}^{\min }, \theta_{L S}^{\max }\right)$.

When $\theta \in \theta\left(0, \theta_{L S}^{\max }\right)$ (i.e., $\left.\theta \in\left(\theta_{L S}^{\min }, 0\right)\right)$ (see Fig.7), outside country $M$ is a capital exporter (importer), while the tax union is forced to be a capital importer (exporter) and thus has to set a positive (negative) harmonized tax rate. In either case, from (7) and (28), the capital price, ${ }_{r}^{C}(L S)=r^{N}-\varepsilon \theta \bar{k} / 2$, is decreasing with $\theta$, because country $M$ imports less capital as $\theta \in\left(\theta_{L S}^{\min }, 0\right)$ 


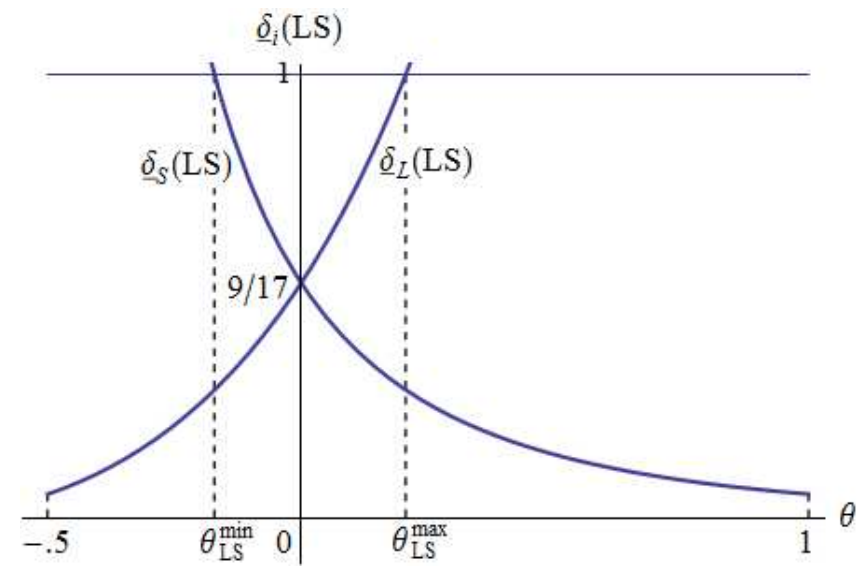

Figure 7: Loci of the minimum discount factors of countries $L$ and $S$.

increases and exports more capital as $\theta \in \theta\left(0, \theta_{L S}^{\max }\right)$ increases. This gives rise to the terms-of-trade as well as capital movement effects. The detailed signs of the respective effects for countries $L$ and $S$ are given as follows:

$$
\begin{aligned}
\frac{\partial u_{L}^{C}(L S)}{\partial \theta} & =\underbrace{\tau^{C}(L S) \frac{\partial k_{L}^{C}(L S)}{\partial \theta}}_{\text {capital movement effect (+,-) }}+\underbrace{\left[\bar{k}_{L}-k_{L}^{C}(L S)\right] \frac{\partial r^{C}(L S)}{\partial \theta}}_{\text {terms-of-trade effect (-) }}=-\frac{1}{8} \varepsilon^{2}(4+3 \theta) \bar{k}^{2}<0, \\
\frac{\partial u_{S}^{C}(L S)}{\partial \theta} & =\underbrace{\tau^{C}(L S) \frac{\partial k_{S}^{C}(L S)}{\partial \theta}}_{\text {capital movement effect (+,-) }}+\underbrace{\left[\bar{k}_{S}-k_{S}^{C}(L S)\right] \frac{\partial r^{C}(L S)}{\partial \theta}}_{\text {terms-of-trade effect (+) }}+\underbrace{r^{C} \frac{\partial \bar{k}_{S}}{\partial \theta}}_{\text {capital endowment effect (-) }} \\
& =-\varepsilon\left[a-2 \bar{k}-\frac{1}{8} \varepsilon(4+5 \theta) \bar{k}\right] \bar{k}<0 .
\end{aligned}
$$

Although the terms-of-trade effects for countries $L$ and $S$ operate in opposite directions, the overall effects on the utilities of the two countries are both negative. The negative sign for country $S$ stems mainly from the negative capital endowment effect. Nevertheless, since the negative capital endowment effect on country $S$ emerges in both the cooperative phase as well as in the Nash equilibrium, it does not have a significant effect on $u_{S}^{C}(L S)-u_{S}^{N}$; instead, the positive terms-of-trade effect dominates and thereby increases $u_{S}^{C}(L S)-u_{S}^{N}$. Hence, the minimum discount factor of country $S$ is decreased so that its incentive to cooperate will be enhanced with $\theta$.

\section{$5 \quad$ Who Gains from Partial Tax Harmonization?}

In this section, we compare the welfare levels of the countries at the fully noncooperative Nash equilibrium and the subgroup Nash equilibria associated with the three types of partial tax harmonization. 
Under the tax union consisting of countries $L$ and $M$, it follows from the participation constraint (36) that the welfare levels of these member countries are unambiguously improved, whereas by utilizing (11) and (31), it is straightforward to show that

$$
u_{S}^{C}(L M)-u_{S}^{N}=-\frac{7}{18} \varepsilon^{2}(1+\theta)^{2} \bar{k}^{2}<0
$$

Namely, the residents of outside country $S$ are always worse off compared to those at the Nash equilibrium. This result is quite intuitive. Although the capital-exporting tax union sets $\tau^{C}(L M)<0$ while the capital-importing outside country $S$ sets a positive $\tau_{S}^{C}(L M)>0$, it holds that $r^{C}(L M)>$ $r^{N}$. This is because the tax union has a bigger share in determining the average tax rate $\bar{\tau}$, and thus it can exert market power on the world capital market. As a result, the capital-exporting tax union can manipulate the net return (i.e., the terms-of-trade effect) in its favor, which ends up reducing the welfare of the outside country.

Similarly, under partial harmonization between countries $M$ and $S$, it follows from (9) and (31) that

$$
u_{L}^{C}(M S)-u_{L}^{N}=-\frac{7}{18} \varepsilon^{2} \bar{k}^{2}<0
$$

which implies that the presence of the tax union deteriorates the welfare of outside country $L$. The tax union consisting of countries $M$ and $S$, which is a capital importer, sets a higher harmonized tax rate compared to the Nash equilibrium tax rate, which lowers the net return on capital to reduce the capital payment borne by the tax union, whereas it harms capital-exporting country $L$ outside the tax union.

Finally, it follows from (10) and (31) that

$$
u_{M}^{C}(L S)-u_{M}^{N}=-\frac{7}{18} \varepsilon^{2} \theta^{2} \bar{k}^{2} \leq 0
$$

Since the tax union consisting of countries $L$ and $S$ may be a capital exporter or importer, it will lower or raise the net return by the increase in $\tau^{C}(L S)$ depending on its exporting position (i.e., the sign of $\theta$ ). In either case, the union can manipulate the net return in its favor, which ends up decreasing the welfare of outside country $M$ except for $\theta=0$.

These results apparently contradict those of Konrad and Schjelderup (1999), Kächelein (2004), Bucovetsky (2009), and Vrijburg (2009) that have shown that partial tax harmonization can improve not only the welfare of the union but also that of the outside countries. The reason for this discrepancy 
is as follows. Since the welfare losses of our model arise only from the inefficiency of production stemming from the tax differentials in asymmetric tax competition rather than from a wasteful raceto-the-bottom tax competition, only union members can enjoy most of the gains from tax coordination in our model, but in their models, every country enjoys the benefit from eliminating a wasteful raceto-the-bottom tax competition. Put differently, since in their models, where higher harmonized tax rates create positive externalities that spill over to all countries, partial tax harmonization internalizes part of the negative fiscal externality arising from inefficiently lower taxes. In contrast, in our model consisting of three heterogenous countries, partial tax harmonization improves the welfare of the only member countries by eliminating production inefficiency, and, moreover, they have opposing incentives to manipulate the prices of capital, i.e., the terms-of-trade effect, in their favor, since the net capital-exporting positions of the tax union and the outside country are opposed to each other, which generates winners (i.e., the tax union) and losers (i.e., the outside country).

Finally, we examine which tax union potentially brings about a Pareto improving allocation compared to the non-cooperative Nash equilibrium allocation. To see this, summing up the welfare gains of all member countries for the respective tax unions and the welfare loss of the non-member country yields

$$
\begin{gathered}
\sum_{i=L, M, S}\left(u_{i}^{C}-u_{i}^{N}\right)=\frac{2}{9} \varepsilon^{2}\left(1+\theta+\theta^{2}\right) \bar{k}^{2}>0, \\
\sum_{i=L, M, S}\left[u_{i}^{C}(L M)-u_{i}^{N}\right]=-\frac{1}{72} \varepsilon^{2}\left(11+38 \theta+11 \theta^{2}\right) \bar{k}^{2}<0, \\
\sum_{i=L, M, S}\left[u_{i}^{C}(M S)-u_{i}^{N}\right]=-\frac{1}{72} \varepsilon^{2}\left(11-16 \theta-16 \theta^{2}\right) \bar{k}^{2}<0, \\
\sum_{i=L, M, S}\left[u_{i}^{C}(L S)-u_{i}^{N}\right]=\frac{1}{72} \varepsilon^{2}\left(16+16 \theta-11 \theta^{2}\right)>0 .
\end{gathered}
$$

These comparisons imply the following:

Proposition 4 (i) Only partial tax harmonization between the most dissimilar countries and full tax harmonization entail a potential Pareto improvement; and

(ii) any partial tax harmonization is Pareto-dominated by the full tax harmonization.

Dissimilar countries bear the largest distortions associated with asymmetric Nash equilibrium tax rates because the tax differential between them is the largest, and so is the gain from tax harmonization between them. Hence, it could entail a potential Pareto improvement even if tax 
harmonization between similar countries does not. In other words, from the viewpoint of society, the terms-of-trade effect, which is strategically manipulated by the tax union, dominates the welfare improvement arising from the elimination of production inefficiency within the member countries.

\section{Extensions}

In this section, we briefly consider two important extensions to check the robustness of our results, such as collusive punishment and minimum tax policy. ${ }^{7}$

\subsection{Collusive Punishment}

We first consider a case in which member countries collude by setting taxes jointly against a deviating country, which maximizes their joint welfare in the punishment phase (see, e.g., Ederington and McCalman (2003) in the context of international free-trade agreements). In the context of our tax competition model, when a member country, say, country $S$, deviates from full tax coordination, (non-cheating) member countries $L$ and $M$ remain in a tax union (i.e., they form a partial tax union) and then choose their joint welfare-maximizing tax rate, $\tau^{C}(L M)$, instead of the Nash equilibrium tax rate to punish deviating country $S$.

It is straightforward to show how the minimum discount factor is affected by the presence of such punishment. We modify the minimum discount factors for the respective countries (22)-(24) by using the utility level of the deviator as $u_{h}^{C}(G)$ in place of $u_{i}^{N}$ as follows:

$$
\widehat{\delta}_{h}(G) \equiv \frac{u_{h}^{D}-u_{h}^{C}}{u_{h}^{D}-u_{h}^{C}(G)}, \quad G \in\{L M, M S, L S\}, h=L, M, S, \text { and } h \notin G .
$$

Furthermore, since it follows from (9)-(11) and (31) that $u_{h}^{C}(G)<u_{h}^{N}$ for $h=L, M, S$, these results, together with (22)-(24), imply that $\underline{\delta}_{h}>\widehat{\delta}_{h}(G)$ for $h=L, M, S$ except for $\theta=0$. Although one may tend to conclude that the harsher collusive punishment would have a strong power to sustain full tax harmonization compared to punishment using the Nash equilibrium tax rate, it may or may not be true. This is because in the punishment phase, the implementation of the collusive punishment itself should be credible in the sense that the member countries must find it optimal to abide by this punishment (i.e., subgame perfect equilibrium). Moreover, although the tax rate under full coordination is indeterminate in the previous section, we here have to choose either a positive or

\footnotetext{
${ }^{7}$ We would like to thank one of the referees of this journal for his or her suggestion as to these extensions.
} 
negative tax rate depending on values of $\theta$ because each partial tax harmonization is credible over a specific range of $\theta$ as shown in Section 4. For example, if $\theta \in\left[-1 / 2, \theta_{M S}\right)$, the only partial tax harmonization between countries $M$ and $S$ is credible. Since this tax union can carry out punishment against country $L$ only, the full tax union has to set a positive tax rate so that country $L$ has the strongest incentive of deviation. Combining (25) with the sustainable conditions derived in Section 4 , it follows therefore that the threshold values of the discount factor are given by

$$
\delta^{*}(\text { collusive })=\left\{\begin{array}{cl}
\max \left[\widehat{\delta}_{L}(M S), \underline{\delta}_{M}(M S)\right] & \text { when } \theta \in\left[-1 / 2, \theta_{M S}\right) \\
\max \left[\widehat{\delta}_{M}(L S), \underline{\delta}_{S}(L S)\right] & \text { when } \theta \in\left[\theta_{L S}^{\min }, 0\right] \\
\max \left[\widehat{\delta}_{M}(L S), \underline{\delta}_{L}(L S)\right] & \text { when } \theta \in\left[0, \theta_{L S}^{\max }\right] \\
\max \left[\widehat{\delta}_{S}(L M), \underline{\delta}_{M}(L M)\right] & \text { when } \theta \in\left(\theta_{L M}, 1\right]
\end{array}\right\} \text {. }
$$

To summarize, the sustainability of full tax harmonization with collusive punishments may or may not be enhanced compared to that with Nash equilibrium punishments, because it can be verified that $\delta^{*}($ collusive $) \gtreqless \delta^{*}$ depending on $\theta$ and $\tau^{C}$.

\subsection{Minimum Tax Rates}

Another interesting tax harmonization policy is to introduce an agreement about a lower bound for admissible tax rates. Kiss (2011) has already shown that the introduction of such a "minimum tax" restricts the tax rate imposed in the punishment phase (which may be greater than the Nash equilibrium tax rate). In this case, the minimum tax policy impairs the ability of countries to punish deviators. This ends up making cooperation harder to sustain a harmonized tax rate. This result holds true for any partial tax coordination in the present model. However, there is an important difference between the Kiss model and ours in that the Kiss model is symmetric in the sense that every country sets the same Nash equilibrium tax rate, while in our asymmetric model, each country sets a different one-shot Nash equilibrium tax rate in the punishment phase, and thus, the lower tax bound may or may not be binding depending on the characteristic of countries (i.e., the size of the country's capital endowment). If it is binding for some country, in particular, for a large country, the sustainable ranges of actual discount factors become more narrow, thus weakening its incentive for cooperation; however, most of the qualitative results obtained in our paper remain unaltered. 


\section{Concluding Remarks}

In this paper, we examined how capital tax harmonization is sustained in a repeated interactions model of tax competition. We have found the following noteworthy results. First, the sustainability of tax harmonization in a subset of heterogenous countries crucially depends on how similar the capital endowment of the median country is to either the large or small country. In general, the larger the heterogeneity among countries, the less likely it is that full as well as partial tax harmonizations will prevail. This finding is consistent with the results based on repeated game settings such as Cardarelli et al. (2002) and Catenaro and Vidal (2006) as well as those based on static settings such as Konrad and Schjelderup (1999), Kächelein (2004), Bucovetsky (2009), and Vrijburg (2009). However, irrespective of whether the models they used is a static or repeated game, there is one important difference between our finding and theirs. Namely, as the capital endowment of the median country approaches the average one, it is more difficult to sustain both the full and partial harmonizations involving the median country, whereas it is easier to sustain the partial tax harmonization excluding the median country. The reason for the former case is that the less skewed the capital endowment of the medium country is, the smaller the amount of capital trade and, consequently, the smaller the amount of benefits from tax harmonization for the union member countries; hence, the median country always has a stronger incentive to deviate than the other partner of a tax union. In the latter case, the less skewed the capital endowment of the medium country outside the tax union, the smaller the amount of net trades between the tax union and the medium country, which alleviates the loss of welfare borne by one of the member countries generated by the terms-of-trade effect. In short, the size of the capital trades (i.e., the magnitude of the terms-of-trade effect) between the union members or between the tax union and the outside country plays a decisive role in determining the sustainability of tax harmonization.

Second, as seen from Fig.8, which illustrates the minimum discount factors of the respective countries under all possible partial tax unions, there exists an interval of positive length for $\theta$ wherein partial tax harmonization is almost impossible, whereas full tax harmonization could be sustained almost everywhere throughout the entire distribution of capital endowment (i.e., $\forall \theta \in[-1 / 2,1])$. Nevertheless, this seemingly counterintuitive result may be not robust if a harmonized tax rate were uniquely determined. In other words, it is the freedom of choosing this tax rate (i.e., the indeterminacy of this tax rate) that enables full tax harmonization to hold for a wider range of $\theta$. However, as noted before, this feature holds under the assumptions of identical technology and 


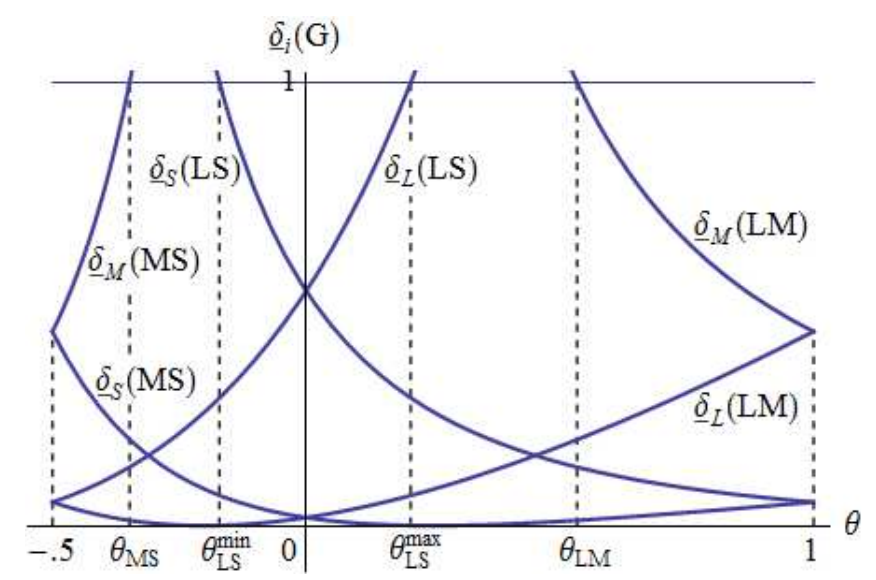

Figure 8: Minimum discount factors of the respective coutries under all partial harmonizations.

linear preferences. Since in reality it is less likely that these assumptions hold, it would be unfair to advocate the superiority of full tax harmonization over partial tax harmonization in this respect.

Third, the likelihood of partial harmonization between any union members does not depend on the total size of the capital endowment in the entire economy (which is measured by $\varepsilon$ ). This noteworthy feature stems from the property of linear utility functions because variations in $\varepsilon$ scale the utility levels of all countries up or down in every phase of the repeated tax competition game, which leaves the minimum discount factors of all member countries invariant. Nevertheless, it remains an open question as to how alternations in $\varepsilon$ affect the sustainability of partial (or full) tax harmonization under more general nonlinear utility functions.

Fourth, the results of this paper may help to explain why the introduction of ECAs is sometimes strongly opposed by outside countries within the EU. According to our results, the tax union and the outside country always have conflicting interests in a such way that the tax union always gains from partial harmonization, while the outside country always loses, because of their opposed net exporting position of capital and because the partial tax union manipulates its harmonized tax rate in its favor. Hence, the introduction of ECAs is not Pareto improving unless the excluded countries in the EU are compensated for their losses. Our result suggests that for the formation of ECAs on selected issues, the outside losers need to be compensated with side payments (recall that the equilibrium outcome of a subgroup Nash equilibrium is potentially Pareto improving only if the country size of the outsider is medium). Although the Treaty of Nice does not require any mechanism of monetary compensation, it would be necessary to design institutions to allow for compensatory transfers to the excluded countries that make it easier for a (qualified) majority of member countries in the EU, which initially do not join an ECA, to agree to form an ECA. 
Finally, the results obtained in this paper critically rely on the restrictive structure of the present model; e.g., a linear utility function and a quadratic production function in a three-country setting. To ascertain the robustness of our results, we have to conduct the same analysis under more general functions and/or include more than three countries. To render the analysis under such a generalized model tractable, we need to conduct a numerical analysis.

\section{Appendix: Proof of Proposition 2}

In order to draw the graphs of $\underline{\delta}_{i}, i=L, M, S$ under full tax harmonization, we first express $\underline{\delta}_{i}$ as a function of $\tau^{C}$; i.e., $\underline{\delta}_{i}\left(\tau^{C}\right)$. When $\theta \in(0,1]$, substituting the lower and upper bound values of $\tau^{C}$ satisfying (16) (i.e., $\tau_{\min }^{C} \equiv-\varepsilon(1+\theta) \bar{k} / 9$ and $\left.\tau_{\max }^{C} \equiv \varepsilon \theta \bar{k} / 9\right)$ into (22), (23), and (24) yields

$$
\begin{gathered}
\underline{\delta}_{L}\left(\tau_{\text {min }}^{C}\right)=\frac{(8-\theta)^{2}}{(4+\theta)(52+\theta)}, \underline{\delta}_{M}\left(\tau_{\text {min }}^{C}\right)=\frac{(8 \theta-1)^{2}}{(1+4 \theta)(1+52 \theta)}, \underline{\delta}_{S}\left(\tau_{\text {min }}^{C}\right)=1 \\
\underline{\delta}_{L}\left(\tau_{\text {max }}^{C}\right)=\frac{(9+\theta)^{2}}{(3-\theta)(51-\theta)}, \underline{\delta}_{M}\left(\tau_{\text {max }}^{C}\right)=1, \underline{\delta}_{S}\left(\tau_{\text {max }}^{C}\right)=\frac{(9+8 \theta)^{2}}{(3+4 \theta)(51+52 \theta)} .
\end{gathered}
$$

Similarly, when $\theta \in[-1 / 2,0]$, the values of $\underline{\delta}_{i}\left(\tau^{C}\right), i=L, M, S$ are given by

$$
\begin{aligned}
& \underline{\delta}_{L}\left(\tau_{\min }^{C}\right)=\frac{(9+\theta)^{2}}{(3-\theta)(51-\theta)}, \underline{\delta}_{M}\left(\tau_{\text {min }}^{C}\right)=1, \underline{\delta}_{S}\left(\tau_{\min }^{C}\right)=\frac{(9+8 \theta)^{2}}{(3+4 \theta)(51+52 \theta)}, \\
& \underline{\delta}_{L}\left(\tau_{\max }^{C}\right)=1, \underline{\delta}_{M}\left(\tau_{\max }^{C}\right)=\frac{(1+9 \theta)^{2}}{(1-3 \theta)(1-51 \theta)}, \underline{\delta}_{S}\left(\tau_{\max }^{C}\right)=\frac{(8+9 \theta)^{2}}{(4+3 \theta)(52+51 \theta)},
\end{aligned}
$$

where $\tau_{\min }^{C} \equiv \varepsilon \theta \bar{k} / 9$ and $\tau_{\max }^{C} \equiv \varepsilon \bar{k} / 9$. Differentiating $\underline{\delta}_{i}\left(\tau^{C}\right), i=L, M, S$ with respect to $\tau^{C}$ yields

$$
\begin{aligned}
\frac{\partial \underline{\delta}_{L}}{\partial \tau^{C}} & =\frac{72 \varepsilon\left(\varepsilon \bar{k}+\tau^{C}\right)\left(11 \varepsilon \bar{k}-9 \tau^{C}\right) \bar{k}}{\left(\varepsilon \bar{k}-3 \tau^{C}\right)^{2}\left(17 \varepsilon \bar{k}-3 \tau^{C}\right)^{2}}>0, \\
\frac{\partial \underline{\delta}_{M}}{\partial \tau^{C}} & =\frac{72 \varepsilon \theta\left(\varepsilon \theta \bar{k}+\tau^{C}\right)\left(11 \varepsilon \theta \bar{k}-9 \tau^{C}\right) \bar{k}}{\left(\varepsilon \theta \bar{k}-3 \tau^{C}\right)^{2}\left(17 \varepsilon \theta \bar{k}-3 \tau^{C}\right)^{2}} \gtreqless 0, \\
\frac{\partial \underline{\delta}_{S}}{\partial \tau^{C}} & =-\frac{72 \varepsilon(1+\theta)\left[\varepsilon(1+\theta) \bar{k}-\tau^{C}\right]\left[11 \varepsilon(1+\theta) \bar{k}+9 \tau^{C}\right] \bar{k}}{\left[\varepsilon(1+\theta) \bar{k}+3 \tau^{C}\right]^{2}\left[17 \varepsilon(1+\theta) \bar{k}+3 \tau^{C}\right]^{2}}<0 .
\end{aligned}
$$

(A1) and (A3) imply that $\underline{\delta}_{L}\left(\underline{\delta}_{S}\right)$ is increasing (decreasing) in $\tau^{C}$ in (16). On the other hand, (A2) implies that $\underline{\delta}_{M}$ is increasing (decreasing) in $\tau^{C}$ if $\theta>1 / 8(\theta<-1 / 9)$ over the tax range (16). Furthermore, evaluating the intersection point (i.e., $\tau^{C}=0$ ), we obtain:

$$
\frac{\partial \underline{\delta}_{L}}{\partial \tau^{C}} \leq \frac{\partial \underline{\delta}_{M}}{\partial \tau^{C}} \text { for } \theta \in[0,1], \text { and }\left|\frac{\partial \underline{\delta}_{M}}{\partial \tau^{C}}\right| \geq\left|\frac{\partial \underline{\delta}_{S}}{\partial \tau^{C}}\right| \quad \text { for } \theta \in\left[-\frac{1}{2}, 0\right]
$$


where $\underline{\delta}_{L}=\underline{\delta}_{M}$ if $\theta=1$ and $\underline{\delta}_{M}=\underline{\delta}_{S}$ if $\theta=-1 / 2$. Moreover, it can be readily seen that when $\tau^{C}>$ $(<) 0, \delta^{*}=\underline{\delta}_{M}$ as long as $\theta \in(0,1](\theta \in[-1 / 2,0))$. To demonstrate this, we first differentiate the minimum discount factors $\underline{\delta}_{M}$ and $\underline{\delta}_{S}$ with respect to $\theta$ and obtain

$$
\begin{aligned}
& \frac{\partial \underline{\delta}_{M}}{\partial \theta}=-\frac{72 \varepsilon\left(\varepsilon \theta \bar{k}+\tau^{C}\right)\left(11 \varepsilon \theta \bar{k}-9 \tau^{C}\right) \bar{k} \tau^{C}}{\left(\varepsilon \theta \bar{k}-3 \tau^{C}\right)^{2}\left(17 \varepsilon \theta \bar{k}-3 \tau^{C}\right)^{2}} \gtreqless 0 \text { iff } \tau^{C} \gtreqless 0, \\
& \frac{\partial \underline{\delta}_{S}}{\partial \theta}=\frac{72 \varepsilon\left[\varepsilon(1+\theta) \bar{k}-\tau^{C}\right]\left[11 \varepsilon(1+\theta) \bar{k}+9 \tau^{C}\right] \bar{k} \tau^{C}}{\left[\varepsilon(1+\theta) \bar{k}+3 \tau^{C}\right]^{2}\left[17 \varepsilon(1+\theta) \bar{k}+3 \tau^{C}\right]^{2}} \gtreqless 0 \text { iff } \tau^{C} \gtreqless 0 .
\end{aligned}
$$

Then, we define $\Phi_{M L}(\theta) \equiv \underline{\delta}_{M}-\underline{\delta}_{L}$ and $\Phi_{M S}(\theta) \equiv \underline{\delta}_{M}-\underline{\delta}_{S}$ with $\Phi_{M L}(1)=\Phi_{M S}(-1 / 2)=0$. If $\theta \in(0,1)$, from (A5), we obtain $\partial \Phi_{M L}(\theta) / \partial \theta<0$ for $\tau^{C}>0$. Similarly, if $\theta \in(-1 / 2,0)$, it follows from (A5) and (A6) that $\partial \Phi_{M S}(\theta) / \partial \theta>0$ for $\tau^{C}<0$. These results, together with (A4), imply that if $\theta \in(0,1]$, then $\underline{\delta}_{M} \geq \underline{\delta}_{L}\left(\underline{\delta}_{M} \leq \underline{\delta}_{S}\right)$ for $\tau^{C}>(<) 0$, while if $\theta \in[-1 / 2,0), \underline{\delta}_{M} \geq \underline{\delta}_{S}$ for $\tau^{C}<0$. Taken together, we can draw Figs. 1-4.

Next, we differentiate $\underline{\delta}_{i}, i=L, M, S$ with respect to $\varepsilon$ and obtain

$$
\begin{aligned}
\frac{\partial \underline{\delta}_{L}}{\partial \varepsilon} & =-\frac{72\left(\varepsilon \bar{k}+\tau^{C}\right)\left(11 \varepsilon \bar{k}-9 \tau^{C}\right) \bar{k} \tau^{C}}{\left(\varepsilon \bar{k}-3 \tau^{C}\right)^{2}\left(17 \varepsilon \bar{k}-3 \tau^{C}\right)^{2}} \lesseqgtr 0 \text { iff } \tau^{C} \gtreqless 0, \\
\frac{\partial \underline{\delta}_{M}}{\partial \varepsilon} & =-\frac{72 \theta\left(\varepsilon \theta \bar{k}+\tau^{C}\right)\left(11 \varepsilon \theta \bar{k}-9 \tau^{C}\right) \bar{k} \tau^{C}}{\left(\varepsilon \theta \bar{k}-3 \tau^{C}\right)^{2}\left(17 \varepsilon \theta \bar{k}-3 \tau^{C}\right)^{2}} \gtreqless 0, \\
\frac{\partial \underline{\delta}_{S}}{\partial \varepsilon} & =\frac{72(1+\theta)\left[\varepsilon(1+\theta) \bar{k}-\tau^{C}\right]\left[11 \varepsilon(1+\theta) \bar{k}+9 \tau^{C}\right] \bar{k} \tau^{C}}{\left[\varepsilon(1+\theta) \bar{k}+3 \tau^{C}\right]^{2}\left[17 \varepsilon(1+\theta) \bar{k}+3 \tau^{C}\right]^{2}} \gtreqless 0 \text { iff } \tau^{C} \gtreqless 0 .
\end{aligned}
$$

\section{References}

Bucovetsky, S. (1991) Asymmetric tax competition, Journal of Urban Economics 30, 167-181.

Bucovetsky, S. (2009) An index of capital tax competition, International Tax and Public Finance 16, $727-752$.

Burbidge, J., J. DePater, G.M. Myers, and A. Sengupta. (1997) A coalition-formation approach to equilibrium federations and trading blocs, American Economic Review 87, 940-956.

Cardarelli, R., E. Taugourdeau, and J-P. Vidal. (2002) A repeated interactions model of tax competition, Journal of Public Economic Theory 4, 19-38.

Catenaro, M. and J.-P. Vidal. (2006) Implicit tax coordination under repeated policy interactions, Recherches Economiques de Louvain 72, 1-17. 
DePater, J. and G.M. Myers. (1994) Strategic capital tax competition: a pecuniary externality and a corrective device, Journal of Urban Economics 36, 66-78.

Ederington, J. and P. McCalman (2003) Discriminatory tariffs and international negotiations, Journal of International Economics 61, 397-424.

Itaya, J., M. Okamura, and C. Yamaguchi. (2008) Are regional asymmetries detrimental to tax coordination in a repeated game setting?, Journal of Public Economics 92, 2403-2411.

Itaya, J., M. Okamura, and C. Yamaguchi. (2014) Partial tax coordination in a repeated game setting, European Journal of Political Economy 34, 263-278.

Kächelein, H. (2004) Capital tax competition and partial cooperation: welfare enhancing or not?, BERG Working Paper Series on Government and Growth \#51, Bamberg University.

Keen, M. and K.A. Konrad. (2013) The theory of international tax competition and coordination, in A.J. Auerbach, R. Chetty, M. Feldstein, and E. Saez (Eds.), Handbook of Public Economics vol.5, pp. 257-328. North Holland: Elsevier.

Kiss, A. (2012) Minimum taxes and repeated tax competition, International Tax and Public Finance 19, $641-649$.

Konrad, K.A. and G. Schjelderup. (1999) Fortress building in global tax competition, Journal of Urban Economics 46, 156-167.

Peralta, S. and T. van Ypersele. (2005) Factor endowments and welfare levels in an asymmetric tax competition game, Journal of Urban Economics 57, 258-274.

Peralta, S. and T. van Ypersele. (2006) Coordination of capital taxation among asymmetric countries, Regional Science and Urban Economics 36, 708-726.

Vrijburg, H. (2009) Partial harmonization in corporate taxes, mimeo, Erasmus University, Rotterdam.

Wildasin, D. E. (1989) Interjurisdictional capital mobility: fiscal externality and a corrective subsidy, Journal of Urban Economics 25, 193-212.

Wilson, J. D. (1991) Tax competition with interregional differences in factor endowments, Science and Urban Economics 21, 423-451. 